\title{
A propósito de las iglesias y mosaicos de Madaba. Problemas sobre la funcionalidad litúrgica de los edificios de culto
}

\author{
Cristina Godoy Fernandez *
}

De las iglesias que el padre Piccirillo nos presenta en su reciente publicación, Chiese e mosaici di Madaba (Jerusalén, 1989) ${ }^{`}$. llama la atención el porcentaje absolutamente aplastante de construcciones de época del llamado renacimiento justinianeo (finales de siglo vi y principios del VII), veintiuna frente a cuatro de epoca omeya. No deja de ser más interesante aún comprobar que en la segunda mitad del siglo vill siguen existiendo comunidades cristianas perfectamente organizadas civil y eclesiásticamente y con el poder económico suficiente como para desarrollar una edilicia importante más de cien años después de la victoria del Islam. La mayoria de las iglesias que se nos presentan $-y$ de las que se ha podido realizar una comprobación arqueológica en sus estratos de abandono-, aunque sean de construcción anterior, perviven hasta bien entrada la época omeya.

Este hecho ha de conducirnos a reconsiderar muy seriamente dónde colocamos los limites para el final del mundo antiguo en estas tierras de Oriente y hacer más flexibles los rigidos esquemas con que los historiadores de la antigüedad tardia han tratado el Islam.

* Departamento de Arqueologia, Universidad de Barcelona.

Piccirillo. M. Chiese e Mosaici di Madaba (Chiese e mosaici di Giordania. II). Studium Biblicum Franciscanum. Collectio Maior, 34. Jerusalen. 1989. Vease recensión en este mismo número. Las ilustraciones que se incluyen proceden de este libro. 
Pero de las aportaciones del trabajo de Piccirillo la que reviste realmente un interés especial para la antigüedad tardia es el espectacular florecimiento edilicio de las comunidades cristianas de las estepas de Madaba en época justinianea. Este hecho debe ponerse en relación con la política religiosa imperial de favorecer la prosperidad del patriarcado de Jesusalén frente al de Antioquia?

Este desbordante porcentaje de iglesias de epoca justinianea se ve en cierta manera deformado en su incremento por el hecho de la inexistencia de edificios de culto en la época anterior. Efectivamente. del corpus de Piccirillo, sólo podemos atribuir a los siglos iv y $\vee$ el primitivo santuario del Memorial de Moisés en el Nebo (fig. 3) y la iglesia de Amos y Casiseos.

¿Debe desprenderse de esto que no existian iglesias en la diócesis de Madaba durante los siglos IV y $\vee$ ? ¿Es que las comunidades cristianas que habitaban estas tierras durante esta epoca eran tan pobres que no han quedado restos de sus centros de culto? Realmente resulta dificil de creer. El territorio de Madaba se vio favorecido por las peregrinaciones a Tierra Santa. Contamos con el testimonio escrito de la peregrina Egeria -en cuyo diario de viaje describe muchas iglesias- y el de Pedro el Ibero ${ }^{3}$.

No podemos olvidar, en este juego de conclusiones, que estamos tratando con cronologías de mosaicos y que estas no tienen que corresponder estrictamente con las fechas de construcción de las iglesias que los contienen, y menos cuando algunas de ellas cuentan con hasta tres pavimentos musivos. Ya hemos hecho alusión en la recensión a la falta de rigor de método arqueológico que resulta de descoyuntar la excavación de los mosaicos del recinto murario que los encuadra, porque, además de darle la integridad como edificio. sólo esta relación entre muros y pavimento puede arrojar alguna luz sobre las posibles refacciones de una misma iglesia.

Si echamos una ojeada a la epigrafía de los mosaicos. que ocupa un lugar muy destacado en la obra de Piccirillo, nos daremos cuenta de

Dounceel-Voute, P. "La Carte de Madaba: Cosmographie. anachronisme et propagande". RB. 95-4 (1988), pags. 519-542. Cfr. tambien W. G. C.. FREND. The Rise of the Monophysite Movement. Chapters in the History of the Church in the fifth and sixth Centuries. Cambridge. 1972.

Una completa bibliografia en JanERAS. S.. "Contributo alla bibliografia Egeriana". Atti del Convegno Internazionale sulla Peregrinatio Egeriae (Arezzo. 23-25 ottobre, 1987). Arezzo, 1990. pags. 355-366. Cfr. tambien Piccirillo. M.. "ll pellegrinaggio di Egeria al Monte Nebo in Arabia”. Ibidem. pags. 193-214 
que los términos más frecuentemente utilizados hacen referencia a refacciones, remodelaciones y pavimentaciones de los edificios de culto. De toda la larga serie epigráfica de los mosaicos del territorio de Madaba, rara vez se hace constar una construcción ex novo. Únicamente podemos senalar tres casos, de los que sólo una vez se explicita una construcción desde los fundamentos, en la iglesia del complejo monástico de ed-Deir en Ma'in. Otro caso tambien excepcional es el de la iglesia de San Elias. cuya cripta, pavimentada entre 595 y 596, junto con el resto de la iglesia formaba parte de una planificación constructiva iniciada por el obispo Sergio y finalizada por su sucesor. Leoncio; no podemos saber. sin embargo, si esta gran construcción se asentaba o no sobre un lugar de culto anterior.

El tercer caso en el que los verbos utilizados por los epigrafistas sugieren una nueva construccion - (oikodomeo. stego. psefocéo y teleo. esto es, edificar. cubrir, pavimentar de mosaico y terminar)- es el correspondiente a la Capilla de San Teodoro, fechada en el 562. Esta capilla forma parte del complejo situado en el atrio de la Catedral de Madaba (fig. 1), y por esta razón debe interpretarse como tal, como una construcción unitaria en un complejo de culto ya existente. En ningún caso podrá extrapolarse la datación de esta capilla al resto del conjunto eclesiástico del que forma parte. Volveremos más adelante sobre la significación litúrgica de la construcción de estas capillas.

Pero, dejando a un lado estas pocas excepciones. la gran mayoria de verbos utilizados por los mosaistas de la Escuela de Madaba significan renovar (neoo), reconstruir (anokodomeo). ordenar (kosmeo). pavimentar con mosaico (osefocéo). y, el más utilizado, teléo, cuya acepción implica más la culminación de una obra que la ejecución completa de la misma. En cualquier caso, no podemos olvidar que estos textos epigráficos se hallan en los soportes musivos, y que éstos son los complementos directos implicitos de los verbos de esa epigrafía musiva.

Me parece que el dato es importante. Si más de un veintena de los edificios cristianos presentados por Piccirillo son objeto de renovación. ordenamiento. reconstrucción y pavimentación, esto quiere decir que antes del "renacimiento justinianeo" existia ya una edilicia cristiana considerable en el territorio de Madaba.

Si bien esto no desmerece en absoluto la trascendencia de la actividad constructiva justinianea de finales del siglo vi y principios del VII. si es conveniente hacer unas cuantas precisiones sobre este axioma histórico-arqueológico. 
En primer lugar, hay que señalar que la presencia de "reconstrucciones" justinianeas, si se nos permite llamarlas ya así. resulta tan abrumadora que llega incluso a borrar de la diócesis la memoria de las construcciones preexistentes. Como consecuencia, puede adivinarse tras esta imposición el brazo ejecutivo de una política religiosa imperial perfectamente planificada. Probablemente tengamos que ver en ello la mano proteccionista imperial de Justiniano al Patriarcado de Jerusalén, frente a las tendencias monofisitas del Patriarcado de Antioquia, favor sentenciado en el II Concilio de Constantinopla en el $553^{4}$.

En segundo lugar, cabe pensar en una reforma litúrgica importante, como resultado de esta imposición político-religiosa. Llama la atención, en este sentido, que, cualquiera que fuera la naturaleza del cambio en el ritual litúrgico de estas iglesias, el espacio arquitectónico se adecuó bastante bien a las reordenaciones internas del nuevo espacio litúrgico.

Esto nos da pie para iniciar un comentario sobre los espacios litúrgicos de estas iglesias de Madaba, comentario que, dicho sea de paso, tanto hemos echado a faltar en la obra de Piccirillo. Ni que decir tiene que un estudio de esta envergadura requiere un conocimiento profundo de la liturgia hierosolimitana, siriaca y constantinopolitana para poder hacer una buena comparación relativa entre las diferentes disposiciones litúrgicas de estas iglesias. Nos vamos a limitar tan solo a formular algunas consideraciones y problemas, esperando que puedan utilizarse por algún orientalista en una futura investigación sobre la arquitectura y la liturgia de Madaba.

Empezaremos por hacer unas cuantas precisiones sobre el escenario propiamente físico, sobre el espacio arquitectónico.

1. En principio todas las iglesias de la diócesis de Madaba tienen tres naves, esto es, todas aquellas de las que el estado de la excavación ha permitido levantar al menos un croquis, sino una buena planimetria.

2. Cabeceras. El tipo de cabecera más frecuente en Madaba es el de cabecera tripartita con un cuerpo central absidado por el interior y dos cámaras laterales de planta rectangular. El porcentaje es realmente sig-

FREND. obra citada. Para la resonancia que tuvo este conflicto en Occidente. BaRBERo. A.. "El conflicto de los Tres Capitulos y las iglesias hispanicas en los siglos vi y vil». Studia Historica. 5 (1987). págs. 123-144. Cfr. tambien Godoy. C. y VILELLA. J.. "De la fides Gothica a la ortodoxia nicena: inicio de la teologia politica visigotica". Los Visigodos. Historia y Civilizacion. Murcia, 1986. pags. 117-144. 
nificativo por cuanto 20 sobre 25 iglesias presentan este tipo de cabecera.

Las excepciones son también interesantes. Tenemos un caso de cabecera tripartita con el cuerpo central rectangular de la misma manera que las cámaras laterales, se trata de la Iglesia del diácono Tomás (fig. 6). Contamos también con casos de cabeceras monoabsidales. Una con ábside rectangular (Iglesia de Lot y Procopio), y dos con los ábsides en formas de exedra, con forma absidal exterior e interiormente (Iglesia del Mapa y la del Monasterio del wadi 'Afrit).

La otra excepcion que debe tratarse obviamente aparte es la cabecera del Memorial de Moises (figs. 3 y 4), por ser un edificio muy peculiar. Presenta una cabecera en trichora y, al parecer, los excavadores la consideran como parte integrante del edificio del siglo IV. Este tipo arquitectónico coincide perfectamente con el lenguaje arquitectónico propio de los monumentos conmemorativos, sean éstos martyria o memoriae, y como tal debe ser considerado ${ }^{5}$.

3. Accesos. Por lo que se refiere a la situación de las puertas, el panorama es de lo más variopinto $y$, por lo tanto, me parece un poco arriesgado extraer conclusiones sobre una planificación constructiva para su utilización litúrgica. Existen iglesias con un solo acceso en fachada; otras tienen dos y tres en fachada siguiendo la alineación de las naves. Otras tienen accesos combinados, bien sea con una puerta en el sur y en fachada, o en el norte y en fachada, o, en fin, dos puertas una en el norte y otra en el sur.

En todo caso esta heterogeneidad en la situación y número de accesos puede ser el indicativo de una estratificación fósil de diferentes programas litúrgicos acumulados en estos edificios de culto. Por ejemplo, la Iglesia de San Esteban en Um er-Rasâs (fig. 9) tiene tres puertas en arco en la fachada que fueron tapiadas no sabemos cuando y adecuaron una entrada central adintelada. Sabemos que las tres puertas en fachada forman parte de la planificación del espacio litúrgico en el uso bizantinoconstantinopolitano ${ }^{6}$, pero no tenemos los datos arqueológicos necesarios para saber cuándo se construyeron estos accesos y cuándo fueron amortizados. Piccirillo se contenta con fechar la iglesia en la segunda mitad del siglo vill por la epigrafía de los mosaicos. Seguramente sea

Grabar. A.. Martyrium. Recherches sur le culte des reliques et lart chretien antique (2 vols.). Paris. 1946.

Mathews, T. F., The Early Churches of Constantinople: Architecture and Liturgy. Pensilvania. 1980 . 
ésta la datación de una sola iglesia de las muchas que enmascara el mosaico y la datación de sus inscripciones. Lamentablemente puede que resulte ya muy dificil, en el estado en que se encuentran muchos de los edificios cristianos de esta zona de Jordania. realizar comprobaciones arqueológicas que puedan ofrecernos argumentos para una buena interpretación a estas refacciones arquitectónicas; pero vale la pena intentarlo.

4. Un aspecto interesante de la arquitectura cristiana de la diócesis de Madaba es que existen numerosos ambientes adosados o adyacentes a las iglesias. Ni que decir tiene que la razón de su existencia radica en la funcionalidad a la que están destinadas, sea esta litúrgica, religiosa o de uso cotidiano. Pero destacamos aqui esta peculiaridad de ambientes circundantes a las iglesias, a nivel estrictamente arquitectónico, porque este fenomeno ha llevado a Piccirillo a identificar un gran numero de monasterios entre los edificios de culto que nos presenta.

Hay casos en que la identificación como un monasterio resulta clarisima. como. por ejemplo. el situado en torno al Memorial de Moisés en el Monte Nebo (figs. 3 y 4) y que Piccirillo ha tenido la suerte de poder excavar en estos últimos años. La identificación de estos ambientes como monasterio se fundamenta nitidamente en las inscripciones donde figuran nombres de monjes e igumenos, más que en una caracterización de las construcciones adyacentes al edificio de culto. Pero en otros casos la interpretación resulta ya más problemática. como. por ejemplo. el del complejo monástico de ed-Deir en Ma in (fig. 7) con tres ambientes adosados en el ala sur de la iglesia. o la del diácono Tomas en el Ayoun Mousa (fig. 6). con dos ambientes dispuestos de la misma manera, por citar dos de los ejemplos más significativos.

No sé que criterios sigue el autor para tales identificaciones, ni tan solo si la excavación de estos ambientes adosados le permite asegurar que alli existía una comunidad de monjes. porque Piccirillo únicamente nos habla en su libro de la comunidad monastica del Memorial de Moisés a la que ya hemos hecho alusión.

En mi opinión esta cuestión es de extremada importancia. Nunca se ha tenido en cuenta que la liturgia monástica resulta bastante diferente de la seguida en las catedrales o en las parroquias. Por esta razón el escenario ha de resultar sensiblemente diferente. ni que sea porque los protagonistas son tambien distintos. Este fenomeno tiene que traducirse de alguna manera en el espacio litúrgico de la iglesia. puede que incluyendo espacios para los coros monásticos, sea en forma de coros elevados, galerías. contracoros. etc. Cabe también la posibilidad de que una 
iglesia a cargo de una comunidad de monjes haga las funciones de parroquia. incluyendo formulas espaciales tan especificas de esta como puede ser un baptisterio, con lo que tendriamos como resultado una forma mixta de iglesia parroquial y monástica.

Estas consideraciones son de gran importancia a la hora de poder establecer unas fórmulas tipológicas arquitectónicas distintivas para iglesias parroquiales y para las monásticas. y no únicamente la existencia de ambientes circundantes a la iglesia. De éstos. si puede demostrarse su utilización cotidiana - que no litúrgica o religiosa-. pueden haber sido ocupados tanto por los feligreses de la parroquia. como por el clero de la vicaria, sin ser estrictamente clero regular.

Pasaremos seguidamente a hacer algunos comentarios sobre los problemas de adecuación del espacio litúrgico en esos edificios de culto de la diócesis de Madaba.

1. Santuario. La identificación del santuario dentro de una iglesia viene siempre determinada por la ubicación del altar. Pocas son las veces que la excavación arqueológica saca a la luz un altar en perfecto estado de conservación. Generalmente el reconocimiento de un altar se establece a partir de las huellas de los stipites, por una fosa de reliquias o por la decoración mucho más solemne de su pavimento.

En las iglesias de la diocesis de Madaba encontramos dos lugares para el emplazamiento del altar: uno en el ábside y otro justo delante de él. Encontramos altares dentro del espacio arquitectónico del ábside en la iglesia de Dhibân, San Sergio de Um er-Rasâs, la iglesia junto a la torre y la iglesia del patio del mismo lugar. Amos y Casiseos, del Diacono Tomás, y San Jorge de el-Mukhayyat. Las iglesias con el altar situado delante del ábside son: la de Lot y Procopio. El Khadir. ed-Deir. En-Nitl y San Esteban de Um er-Rasàs.

Si buscamos una aproximación cronológica para la interpretación de esta divergencia de escenarios liturgicos a partir de las dataciones que Piccirillo establece a través de la epigrafía de los mosaicos, nos encontramos que la mayoria de estas iglesias las data en epoca justinianea. excepto la de San Esteban de Um er-Rasâs, que la situa en epoca omeya. La arqueología. en este caso, no ofrece ninguna prueba que pueda reflejar un cambio de tradición litúrgica en esa diferencia de ubicación del santuario.

La coexistencia de ambos emplazamientos del santuario se demuestra en la misma epoca justinianea. cuando se repavimentan estos edificios, prueba irrefutable de que todas estas iglesias se estaban utilizando 
para el culto. Pero este hecho no nos dice nadja de si tenian un origen distinto por una funcionalidad especifica - estoy pensando en la asociación del altar delante del ábside con el synthronon, del cual hablaremos más adelante-. o bien por responder a necesidades de tradiciones litúrgicas distintas impuestas en el territorio de Madaba en diferentes momentos históricos.

En relación a esa diacrónica imposición de usos litúrgicos en el territorio de Madaba, diremos que la ubicación de altar dentro del ábside se ha tenido siempre -entre los especialistas - como una caracteristica propia de las iglesias siriacas del norte, mientras que la situación del altar justo delante del ábside se tiene por característica en Apamea y Siria del sur $^{7}$.

Una cuestión digna de mencionarse es la existencia de fosas de reliquias bajo el altar, cosa que no sabemos en qué momento se produce ni cómo tenemos que relacionarlo con las costumbres liturgicas. Generalmente, la tradición siriaca es bastante reacia a la colocación de reliquias bajo el altar en su consagración, sino que opta por la conservación de las mismas en las cámaras laterales -generalmente el diakonikon, como veremos después- $y$, en definitiva, por una manera muy peculiar de prestar las reliquias a la veneración de los fieles.

El problema sigue existiendo puesto que no contamos con argumentos arqueológicos que nos atestiguen cuándo se colocan esas fosas de reliquias bajo el altar. Sin embargo puede tomarse como un indicio cronológico que algunos de estos loculi destruyen parte de los motivos decorativos de los mosaicos sobre los que se instalan. Si aceptamos que el momento de esplendor de estas pavimentaciones musivas en Madaba corresponde a la época justinianea, según Piccirillo, tendremos que concluir que los altares con relicario corresponden más o menos a esta época, es decir, mediados del siglo VII.

Concuerda, además, con esta hipótesis el hecho de que la tradición litúrgica bizantina contempla la deposición de reliquias en la consagración de los altares ${ }^{8}$. No sé hasta qué punto puede relacionarse con este

Duval. N. "Les églises de Jordanie: decor et liturgie". Mosaiques Byzantines de Jordanie. Catalogue de l'Exposition au Musee de la Civilisation Gallo-Romaine de Lyon (février-mai. 1989). Lyon. 1989. pags. 197-206: esp.. pag. 201. Lamentablemente no hemos podido conseguir la tesis de DOUNCEEL-VOUTE. P. Les pavements des eglises byzantines de la Syrie et du Liban. Decor. archeologie et lifurgie. Louvain-la-Neuve. 1988.

NussBaum. O.. Der Standort des Liturgen am christlichen Altar vor dem Jahre 1000. Eine archäologische und liturgiegeschtliche Untersuchung. Bonn. 1965, pag. 138 y ss. 
A propósito de las iglesias y mosaicos de Madaba. Problemas ...

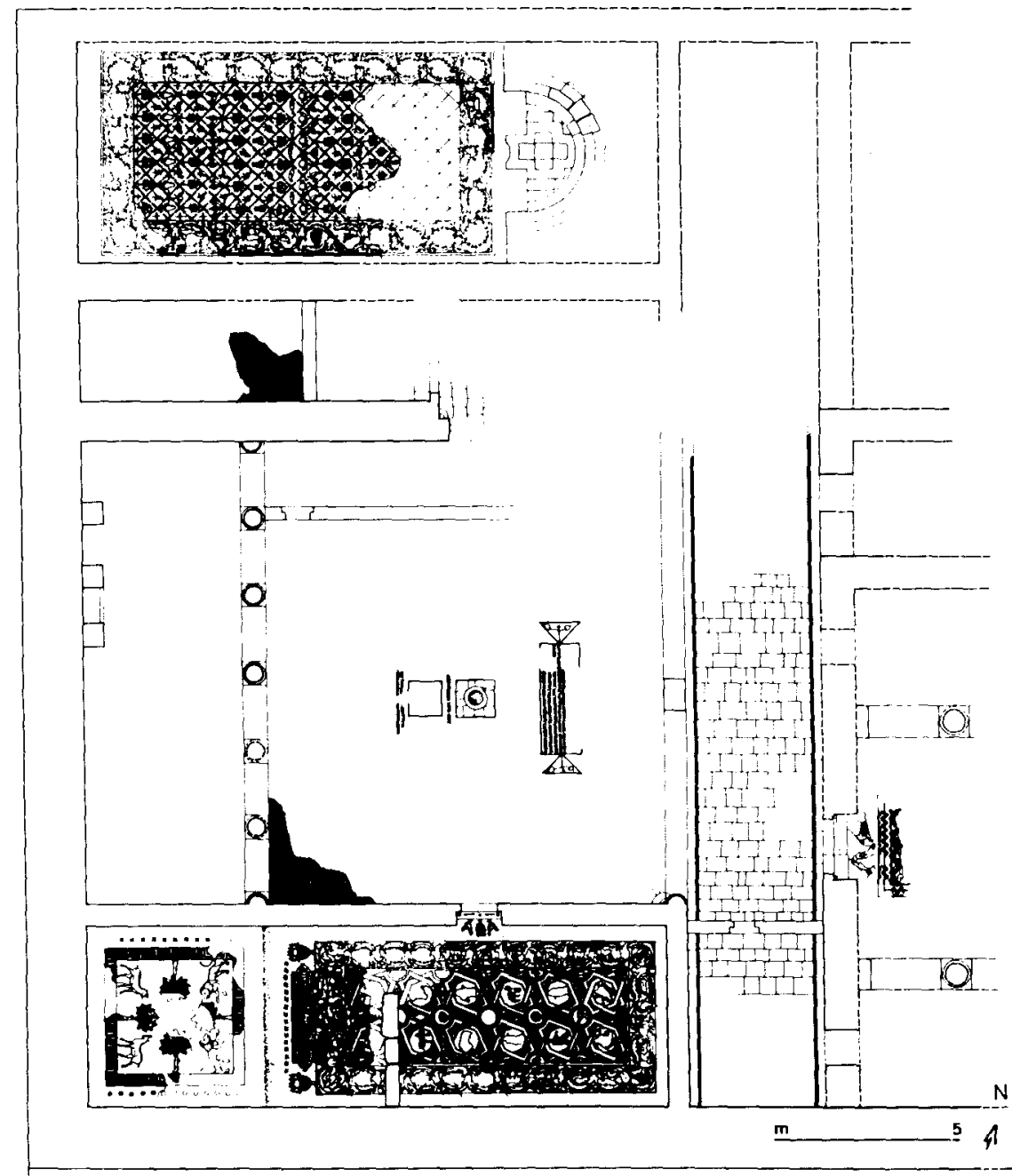

Fig. 1. Atrio de la Catedral de Madaba. 
hecho la imposición imperial justinianea en política religiosa a favor del Patriarcado de Jerusalén en contra del de Antioquia. Pero cuando una iglesia vuelve a consagrarse es que se cree debe volverse a purificar por haber estado en manos de infieles o herejes. Y precisamente todas las sedes dependientes del Patriarcado de Antioquia eran sospechosas de seguir la herejía monofisita.

Si aceptamos esta interpretación, tenemos que pensar también que esta reconsagración de las iglesias -o algunas de ellas - se ajusta a la politica de reconstruccion, consonante con el esplendor de la escuela de mosaistas de la región que se impone de manera arrolladora en época justinianea, cuyo objetivo principal parece ser el de tachar los escenarios litúrgicos más característicos de la tradición litúrgica antioquena.

El baldaquino sobre el altar es una estructura extraña en Madaba, sólo aparece en la Iglesia de Dhibân.

2. Synthronon. Esta estructura litúrgica es bastante frecuente en el territorio de Madaba: la encontramos en la Iglesia de los Santos Apóstoles (fig. 2), en la de El Khadir (fig. 8), en el Memorial de Moisés (figs. 3 y 4), en la de Amos y Casiseos, en En-Nitl, en San Sergio de Um erRasâs (fig. 9) y en la Catedral de Madaba (fig. 1).

La abundancia de iglesias con este espacio litúrgico en una misma diócesis episcopal plantea algunos problemas en torno a la utilización de esta disposición en el ábside de la iglesia. Por lo pronto, la inmediata deducción de que el synthronon estaba siempre relacionado con la catedral, con la entronización del obispo junto al clero durante la celebración de la misa, queda definitivamente descartada. Su existencia no es únicamente un privilegio episcopal, propio de la catedral.

La presencia de un synthronon en el Memorial de Moisés puede justificarse bastante bien por las connotaciones de prestigio que entraña un gran centro de peregrinaje en el que la presencia del obispo de Madaba debia ser frecuente, como atestigua la epigrafía. El gran tamaño de esta instalación sugiere, por otra parte, la asistencia de un gran número de miembros del clero, fuera éste catedralicio o monástico del cenobio que existía en el propio Monte Nebo.

Exceptuando la Catedral y el Memorial de Moisés, el resto de synthronon debe cumplir una funcionalidad que no sea la de entronización del obispo y su clero. Puede pensarse que la presencia de esta catedra fuera dispuesta en algunas basílicas en previsión de las visitas pastorales que el obispo realizara a esas iglesias. Pero me parece mucho más sencillo interpretar este espacio litúrgico - fuera del contexto de la sede 
A propósito de las iglesias y mosaicos de Madaba. Problemas ...

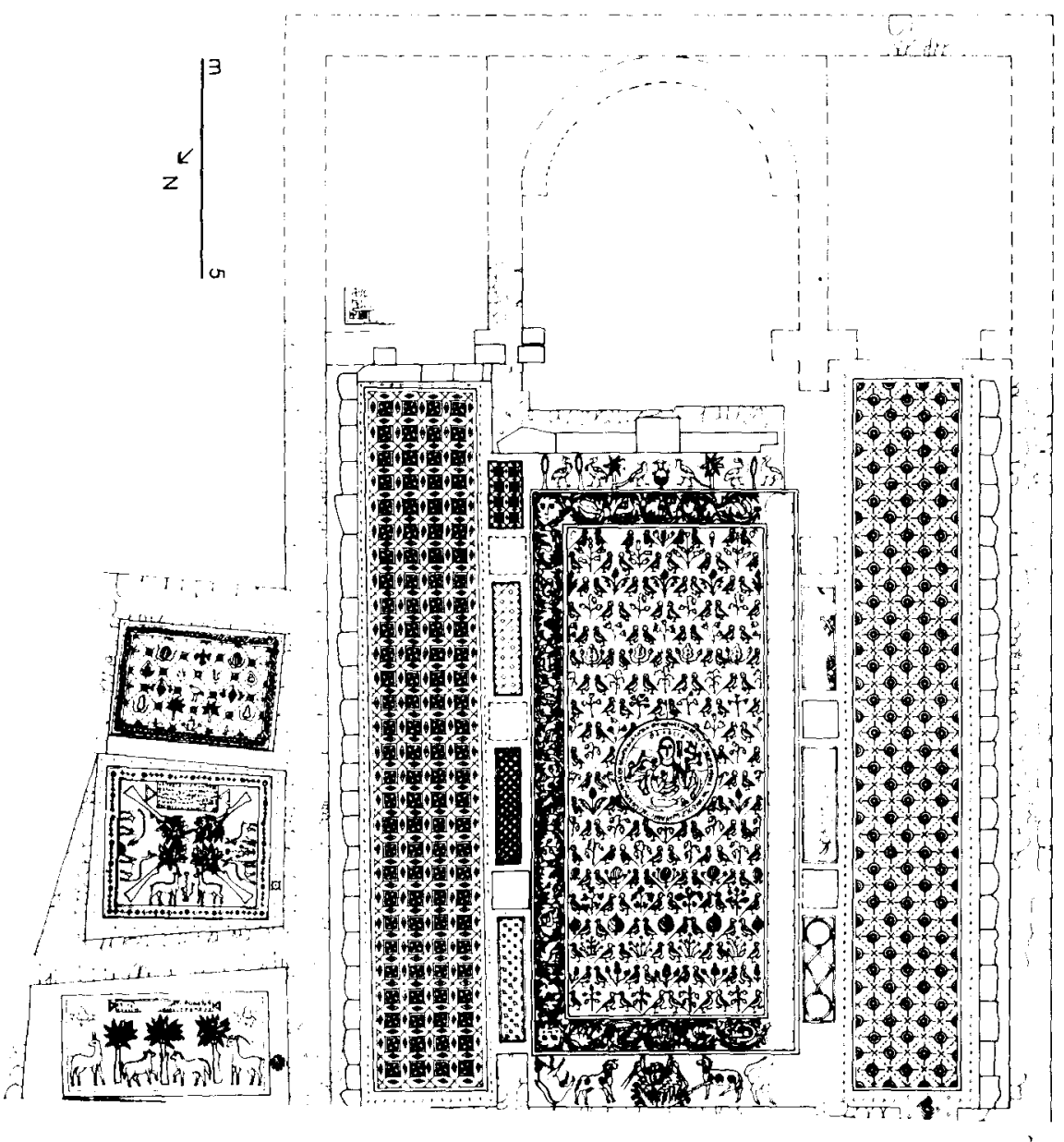

Fig. 2. Iglesia de los Santos Apóstoles de Madaba. 
episcopal - con su equivalente en una parroquia, es decir, la entronización del presbitero y diáconos que estuvieran al frente de la misma.

En algunos casos, el banco semicircular adosado al ábside se interrumpe en el centro dejando un espacio vacio. Duval ${ }^{9}$ lo entiende como el lugar reservado a la cátedra móvil del obispo; esta movilidad escenográfica de la sede del obispo encuentra el guión en muchas tradiciones litúrgicas. El problema no resulta tan sencillo, sin embargo, cuando en lugar del trono existe una plataforma excesivamente baja con algún tipo de engarce dificilmente adaptable a un trono móvil, o, también, cuando la sede está exageradamente alta con respecto al nivel del banco semicircular.

En efecto, en San Sergio de Um er-Rasâs (fig. 9) la banqueta presbiterial está dividida en dos segmentos por una plataforma cuadrada saliente y enlucida con un agujero central ${ }^{10}$. Las dimensiones de este cuadrado - tomadas directamente de la planta, porque no figuran en la descripción - son de unos 60 por $70 \mathrm{cms}$, lo que constituye una buena base para una sede móvil. Pero lo que resulta dificil de interpretar es el orificio practicado en el centro de la misma. Si se tratara de un trono no necesitaría ningún engarce, 0 , al menos, requeriría varios de ellos. Es más probable que en ese agujero se engarzara un solo soporte cilindrico. como, por ejemplo, el de un facistol para sostener los Evangelios o, más probablemente, el leño de una cruz. La entronización de los Evangelios, sin embargo, suele hacerse en un trono-facistol de mamposteria en los bemata siríacos, por lo que me convence más que sea una cruz. Ambos simbolizan la presencia real de Cristo y representan la presidencia de la asamblea litúrgica, en la tradición sirio-bizantina. Se trata de la denominada hetoimasia, tantas veces representada en la iconografia bizantina. De ser cierta esta identificación tendriamos la primera constatación arqueológica de esta disposición litúrgica ".

En algunas basilicas las banquetas semicirculares del synthronon se reemplazan o complementan con dos bancos rectilíneos situados a uno y otro lado del altar. Es el caso de la Iglesia de Amos y Casiseos y la de San Jorge (fig. 5), ambas en el Mukhayyat. La colocación de estos bancos junto al altar es una costumbre litúrgica propia de Grecia y los

Duval. artículo citado. pág. 199.

Piccirillo. obra citada. pag. 273.

"Cfr. mi contribución. "El escenario arquitectónico de la celebración de los concilios hispano-visigodos". Congreso Internacional del XIV Centenario del Concilio III de Toledo (Toledo. mayo de 1989). en prensa. Sobre la hetoimasia. Demus. O.. Byzantine Mosaic decoration. Aspects of Monumental Art in Byzantium. New Rochelle. Nueva York. 1976. 




Fig. 3. Memorial de Moisés, siglos IV-V. 
Balcanes ${ }^{12}$. y poco frecuente en Jordania. Ignoro si esta disposición especial puede tener alguna relacion con los posibles cambios en la imposición o perduración de algún uso litúrgico. pero me inclino a creer que. si ha tenido alguna vía de acceso en las tierras de Madaba. esta tuvo que producirse bajo la egida de la politica imperial religiosa justinianea.

3. Bema. Al hablar de bema nos referimos al espacio delimitado por canceles y de utilización exclusiva por el clero. excepto en ocasiones muy puntuales. De hecho los canceles siempre limitan el acceso a los fieles y definen los espacios mas sagrados de un edificio de culto.

La terminologia tradicional arqueológica le ha dado varios nombres a estos ámbitos utilizados por el clero. La mas general diferencia el sanctuarium del quadratum populi como división de un espacio sagrado de otro más sagrado al cual no tienen acceso los fieles. aunque las fuentes litúrgicas no tienen una denominación general. sino que varía según las tradiciones.

Esta variación puede observarse también sobre los monumentos. El lugar ocupado por el clero puede dividirse por categorias: esto es. puede haber una basilica con synthronon en el ábside y un espacio reservado entre el altar y las naves. uno ocupado por las jerarquías de la iglesia. y el otro por las ordenes menores. por la schola cantorum. etc. A este espacio los arqueólogos lo han denominado convencionalmente coro. para diferenciarlo del presbyterium - situado generalmente en el ábside-, y del sanctuarium como emplazamiento del altar.

Sin embargo, el problema es más grave cuando el espacio arquitectónico del ábside está ocupado por el altar. porque el lugar ocupado por los oficiantes ha de desplazarse hacia las naves. Esta es la argumentación que sigue $\mathrm{T}$. Ulbert para ubicar el presbyterium de las iglesias hispanicas, por ejemplo, entre el abside y las naves ${ }^{1.3}$. No obstante. este vocablo no existe en la liturgia hispanica. pero tiene, en cambio. un término para definirlo: el chorus ${ }^{14}$.

PALLAS. D., "L'edifice cultuel chretien et la liturgie dans l'llyricum Oriental". Actes du X C.I.A.C. (Thessalonique 1980). Ciudad del Vaticano. 1984. pags. 85-158. Cfr. la critica que hizo Post. P.. a este articulo. "La liturgie en tant qu'architecture? Remarques sur la relation entre le Testamentum Domini Jesu Christi et l'architecture des eglises dans I'llyricum Oriental". Bijdragen. 42 (1981) pags. 392-420

"ULBERT. T.. Fruhchristliche Basiliken mit Doppelapsiden auf der Iberischen Halbinsel. Studien zur Architektur- und Liturgiegeschichte. Berlin. 1978. pag. 128

Puertas Taicas. R.. Iglesias hispanicas (siglos IV al VIII). Testimonios literarios. Ma drid. 1975. pags. 100-102. 
A propósito de las iglesias y mosaicos de Madaba. Problemas ...

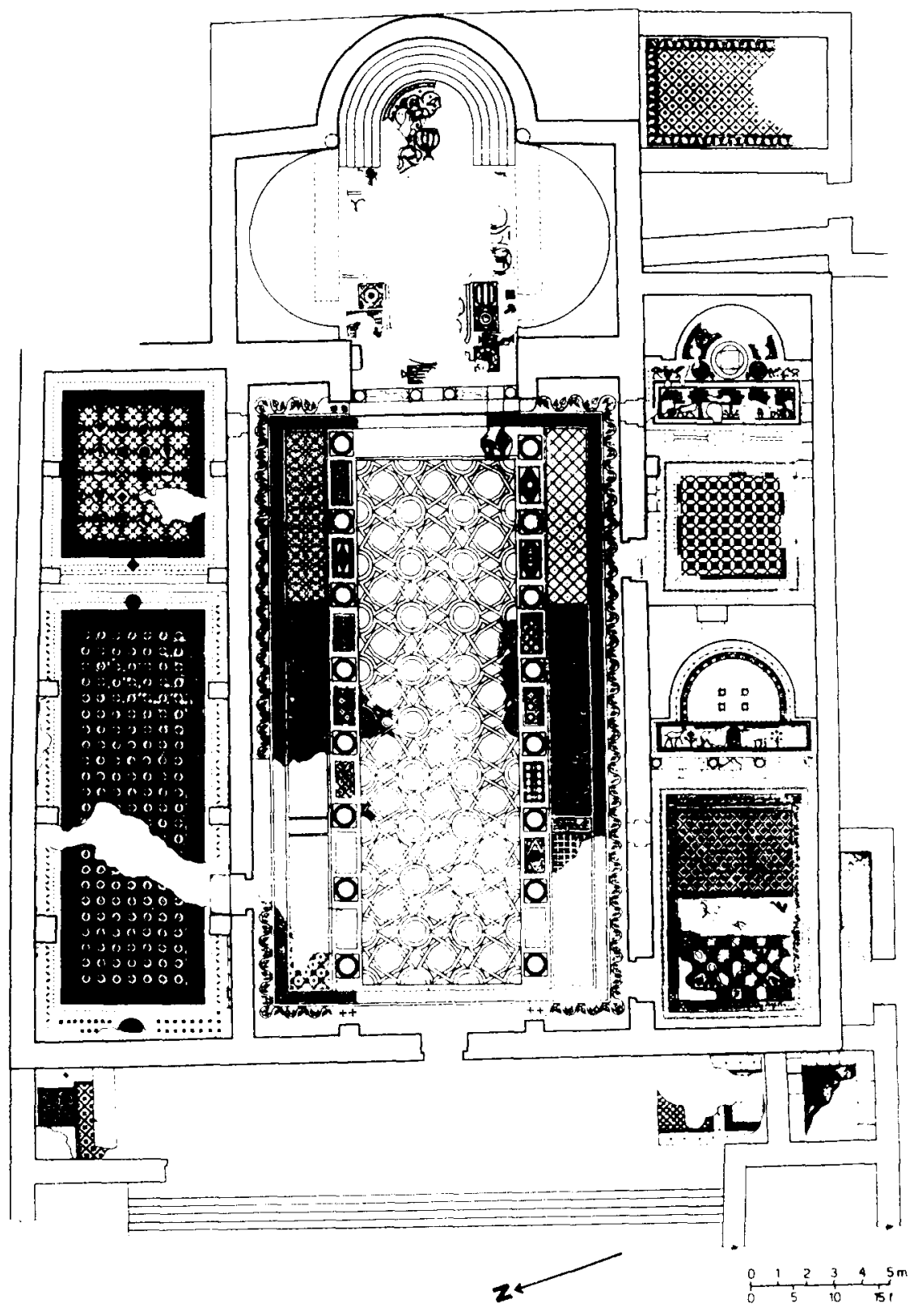

Fig. 4. Memorial de Moisés, siglos VI-VII. 
En las iglesias de Madaba existen casos de iglesias que tienen el santuario dentro del ábside, y tienen además synthronon, como en la iglesia de Amos y Casiseos o la de San Sergio de Um er-Rasâs (fig. 9). con lo cual tendríamos dos espacios litúrgicos en un mismo espacio arquitectónico: el presbiterio y el santuario en el ábside.

Lo que si sabemos claramente, en las iglesias de Madaba. es que al espacio ubicado entre el altar y las naves —rodeado por cancelesse le llama bema. Una inscripción del mosaico de la iglesia de San Esteban de Um er-Rasâs hace constatar su pavimentación en el 756 de la era cristiana ( $p$ psifosis tou agiou bimatos"). Evidentemente el espacio es utilizado sólo por el clero y corresponde directamente con el chorus hispánico. La correspondencia como espacio litúrgico es también directa con su homólogo en la tradición de Siria del norte, con una funcionalidad parecida - que no idéntica-, aunque ubicado el bema siríaco en medio de la nave central ${ }^{15}$.

Una observación de los bemata de la iglesias de Madaba y de su territorio diocesano nos demuestra la existencia de unas remodelaciones, en algunos casos, en las que se extiende este espacio sobre la nave central. Este fenómeno puede detectarse en la iglesia de El Khadir (fig. 8), San Juan y Elias en Kattâbiyah y la Catedral de Madaba.

A pesar de no disponer de ninguna información arqueológica sobre una fecha aproximativa de tales reformas, es obvio que, si existen obras de transformación, deben darse tambien varias fases de vida en la iglesia. La tendencia, sin embargo, es la de ampliar estos bemata. incluso recubrirlos de un nuevo pavimento musivo que, según la epigrafía y el estudio de Piccirillo, hay que datar desde época justinianea hasta la segunda mitad del siglo vill.

La pregunta inmediata que se suscita a todo esto es: ¿por qué se amplian estos espacios dedicados al clero? La respuesta lógica que se me ocurre es porque deben aumentar en número y. quizá también. en prestigio. Los mismos monumentos son prueba de las opulentas comunidades cristianas que ocupaban el territorio de Madaba. La clerecia era muy importante en poder $y$ en prestigio en estas iglesias, por lo que fueron jerarquizándose y aumentando en número. La epigrafia de Madaba y, en general, de toda esta zona del Oriente Próximo, asi lo de-

Lassus. J., y TChalenko. G.. "Ambons syriens". CA., 5 (1951), págs. 75-122. TCHA. IENkO. G.. Villages antiques de la Syrie du Nord (3 vols.). Paris, 1953-1958. Este mismo autor anuncia la próxima publicación de un corpus de basilicas siriacas con bema (Eglises syriennes a bema) en la serie del Institut Francais d'Archeologie du Proche Orient. 
muestra. Tenemos que pensar también en las órdenes monásticas, que seguramente se emplazarian en el mismo espacio del bema, pero no en iglesias de uso únicamente monástico, sino en parroquias donde también oraban los monjes, como, por ejemplo, en el Memorial de Moisés, donde el bema es extraordinariamente grande y no por ser un gran centro de peregrinación - el bema está vedado a los fieles-, sino por tener un gran número de clero regular y monástico.

La extensión sobre las naves de los bemata aprovecha, en algunas ocasiones (como la iglesia de El Khadir, fig. 8), algunas columnas de la nave central. De esto puede deducirse también una transformación del sistema de cubrición de la cabecera, cuya evaluación requiere un examen arqueológico más exhaustivo. Quizá deba entenderse que el ábside adquiere más solemnidad, a la manera de una exedra cubierta por un baldaquino, cosa que iría muy bien con el carácter grandilocuente que adquiere el ábside con el synthronon en el ritual de la hetoimasia bizantina, de la que ya hemos hablado. De todas formas, su correcta interpretación requiere un análisis in situ.

4. Ambones y mesas de ofrendas. El lector se preguntará asombrado por qué reunimos bajo un mismo epigrafe dos disposiciones espaciales con una funcionalidad litúrgica tan diferente. La razón es muy clara: las improntas físicas de estas instalaciones llevan a menudo a una confusión, como en la Iglesia de Amos y Casiseos, en la que Piccirillo lo interpreta como un ambón ${ }^{16}$, miembras Duval lo cree una mensa de ofrendas ${ }^{17}$.

El ambón, sin embargo, suele tener unas formas más caracteristicas en esta zona de Jordania que las mensae destinadas a recoger los oblata de los fieles. Mientras de éstas las huellas son sólo los stipites o soportes cilíndricos para aguantar una losa o tabla de madera, los ambones acostumbran a ser más sofisticados en su construcción. Son estructuras elevadas que arrancan del cancel, desde el que se accede por unas escaleras a una plataforma que descansa sobre columnillas que se asientan a su vez en la nave. En cuanto a las improntas de esta disposición que la hacen identificable como un ambón, diremos. que las columnillas se engarzan en una losa que descansa directamente sobre el pavimento de la nave, losa que puede ser poligonal o circular ${ }^{18}$.

16 Piccirillo, obra citada, pág. 189.

17 Duval, articulo citado, pag. 203.

18 Resulta interesante, en este sentido. la exportación de estos elementos del mobiliario liturgico como lo demuestra el hallazgo del pecio de Marzameni. KapitaN. G., "Elementi architettonici per una basilica dal relitto navale del VI sécolo di Marzameni (Siracusa)". XXVII Corso di Cultura sull'Arte Ravennate e Bizantina, Ravena, 1980, pags. 71-136. 


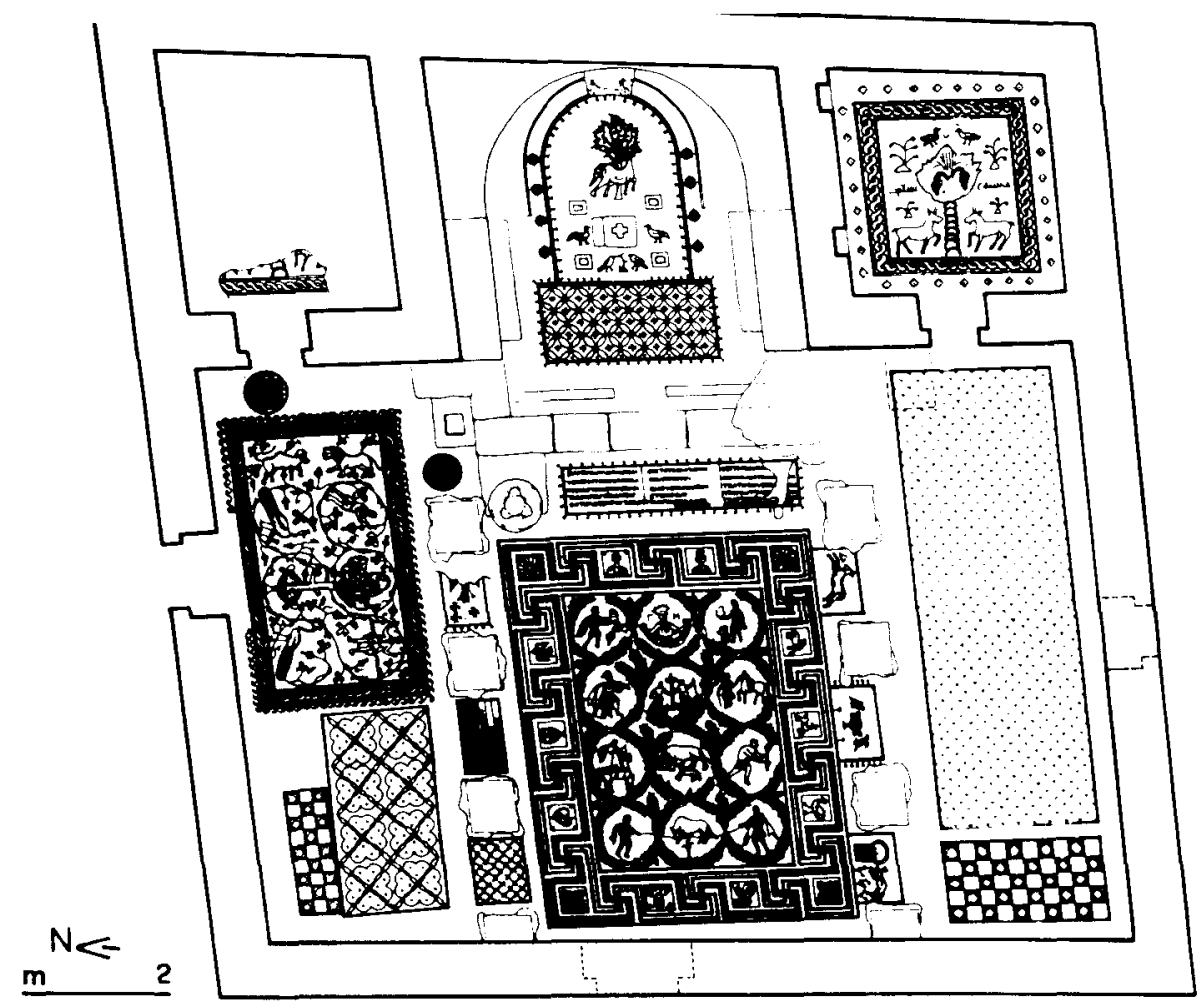

Fig. 5. Iglesia de San Jorge de El-Mukhayyat.

La función litúrgica del ambón es la de realizar las lecturas y las letanías diaconales, $y$, a veces -no siempre - es el lugar de la predicación. Es el espacio donde se realiza la liturgia de la palabra. Ni las formas ni el emplazamiento de esta disposición litúrgica siguen un esquema rígido en las diferentes regiones del orbe cristiano, ni aun en el territorio diocesano de Madaba.

En esta zona sólo hemos contabilizado cinco ambones en un total de veinticinco iglesias. En unas se sitúa en el lado norte dei cancel y la nave del evangelio: San Jorge de el Mukhayyat (fig. 5); y en otras entre 
algunos casos. como en la Iglesia de Amos y Casiseos y la de San Sergio de Um er-Rasâs este espacio litúrgico coexiste con la instalación de un synthronon en el fondo del abside, desde donde sabemos que muchas veces se hacia la predicación ${ }^{19}$; podemos entender que en estas iglesias concretamente se haria distición entre el escenario de las lecturas y el de la predicación.

El espacio de la liturgia de la Palabra tiene una gran heterogeneidad de usos y disposiciones en época paleocristiana. En los Balcanes ${ }^{20}$. en Asia Menor y en Tripolitania se utiliza un gran ambón en mármol (accesible normalmente por dos tramos de escaleras). situado en la nave, fuera del santuario, en un lugar que varia según las provincias: en el norte. en el eje o en el sur, y unidos al santuario por un pasillo llamado solea. En Siria del norte la liturgia de la Palabra se desarrolla en el ambón o bema siríacos ${ }^{21}$. Las regiones alpinas y en Renania emplean una plataforma poligonal o circular situada en el eje, delante del cancel, a la que se accede por un pasillo corto. En Cirenaica encontramos una pequeña tribuna, enganchada al cancel, generalmente en el lado sur. justamente como en Jordania y en Palestina ${ }^{22}$.

Esta heterogeneidad de disposiciones para una misma necesidad iitúrgica en las diferentes regiones y el uso no prescriptivo en una misma diócesis demuestran la flexibilidad que contempla el escenario de las ceremonias de lectura y predicación. Por otra parte, apenas contamos con datos cronológicos sobre las instalaciones de ambones que puedan arrojar un poco de luz sobre las fechas de imposicion de nuevos usos o costumbres litúrgicas.

Duval y Piccirillo señalan el caso del ambón de la Iglesia de San Sergio de Um er-Rasás, como un buen indicio cronológico para la datación de estas disposiciones. El ambón fue colocado con posterioridad al mosaico --datado en el 586- y cubrió una de la figuras de las cuatro estaciones que protegió de la destrucción iconoclasta ${ }^{2.3}$. Duval, apoyándose en esta datación y comparandola con la de la proxima iglesia de San Esteban, donde el ambon tiene un lugar reservado en el diseño del mosaico datado en el siglo vill. concluye que este tipo de disposiciones cubre una cronologia a partir del siglo $\mathrm{VI}$, siendo ya normal en el vill ${ }^{2.4}$.

"Olivar, A. "La predicacion patristica: circunstancias de lugar". II Reunio d Arqueologia Cristiana Hispanica. (Montserrat, 1978). Montserrat-Barcelona. 1982. paginas 197-211. JakoBs. P. H. F. Die fruhchristlichen Ambone Griechenlands. Bonn. 1987.

Supra. nota 15.

Duval. articuio citado. pags. 202-203.

PICCIRILLO. obra citada, pags. 276-279

Duval. articulo citado. pag. 203. 


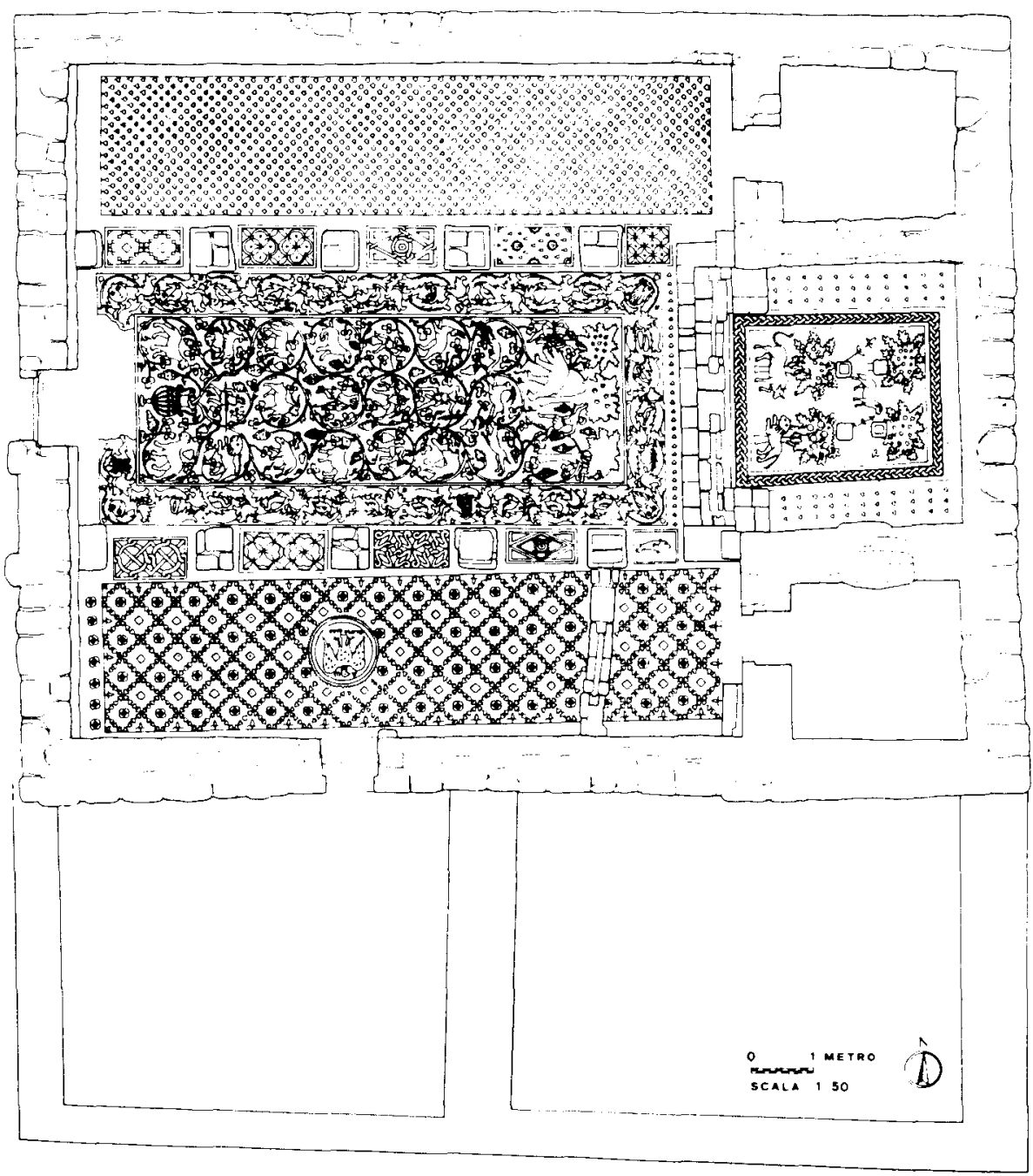

Fig. 6. Iglesia del diácono Tomás en El Ayoun Mousa.

Me parece un poco arriesgado extrapolar dataciones de un caso concreto, como es el de Um er-Rasâs, que pueden ser muy válidas para esta iglesia, pero no permite generalizarlas para el resto de iglesias, ni de Jordania, ni del resto de las regiones del orbe cristiano. Una buena datación requiere un exhaustivo análisis arqueológico comparado con una 
buena encuesta de las fuentes escritas y de los diferentes usos litúrgicos seguidos en una misma región. Considero que únicamente después de realizar metódicamente este análisis podrá llegarse a conclusiones cronológicas y de diferentes usos litúrgicos sobre la instalación de los ambones.

En lo que se refiere a las mensae de ofrendas, Piccirillo las señala en Amos y Casiseos y en ed-Deir de Ma'in, adosada esta última en la cuarta columna del sur (fig. 7). Ya hemos señalado la confusión que existe en torno a la identificacion como ambones o mensae de ofrendas, confusionismo que se extiende también a la Capilla de la Theotokos en el Nebo, donde Piccirillo ve un baldaquino ${ }^{25}$. y Duval, una mensae de ofrendas ${ }^{26}$. Las mensae de ofrendas están íntimamente relacionadas con las prothesis, cuya funcionalidad preferimos analizarla con la de las cámaras adosadas al ábside.

5. Pastophoriae o cámaras adosadas al ábside. Como hemos visto al analizar el espacio arquitectónico, la mayoría de las iglesias de Madaba se caracterizan por tener cabecera tripartita, es decir, con un ábside central y dos cámaras adosadas a uno y otro lado. Los especialistas en arqueologia cristiana relacionan casi inmediatamente esta formula arquitectonica con la funcionalidad litúrgica de las pastophoriae, nombre genérico con el que se conoce a estos dos ambientes: uno, situado en el norte, abierto a la nave, donde se realiza la entrega de los oblata antes de la Misa. llamado prothesis; el otro, situado en el sur, con acceso al bema, que cumple la función de sacristía, llamado diakonikon.

La planificación de estos espacios litúrgicos está contemplada en la edición que Jacobus Goar hizo ca. 1630 del ritual de la iglesia griegaortodoxa de Chiros, y utilizando el Codex Barberini, el Euchologion sive Rituale Graecorum, datado en el siglo VIII y proveniente de las comunidades bizantinas de Sicilia y del sur de Italia ${ }^{27}$. El problema se plantea cuando queremos remontarnos a epoca paleocristiana y comprobar si este esquema de las pastophoriae coincide con las realidades arqueológicas concretas de los edificios.

Un planteamiento correcto del tema es el que ha realizado G. Descoeudres en su estudio de las pastophoriae en el Oriente sirio-

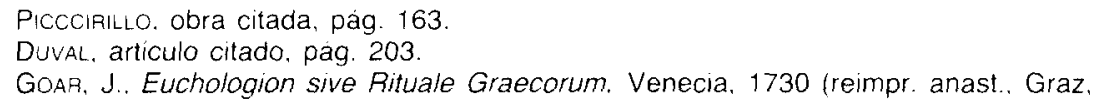




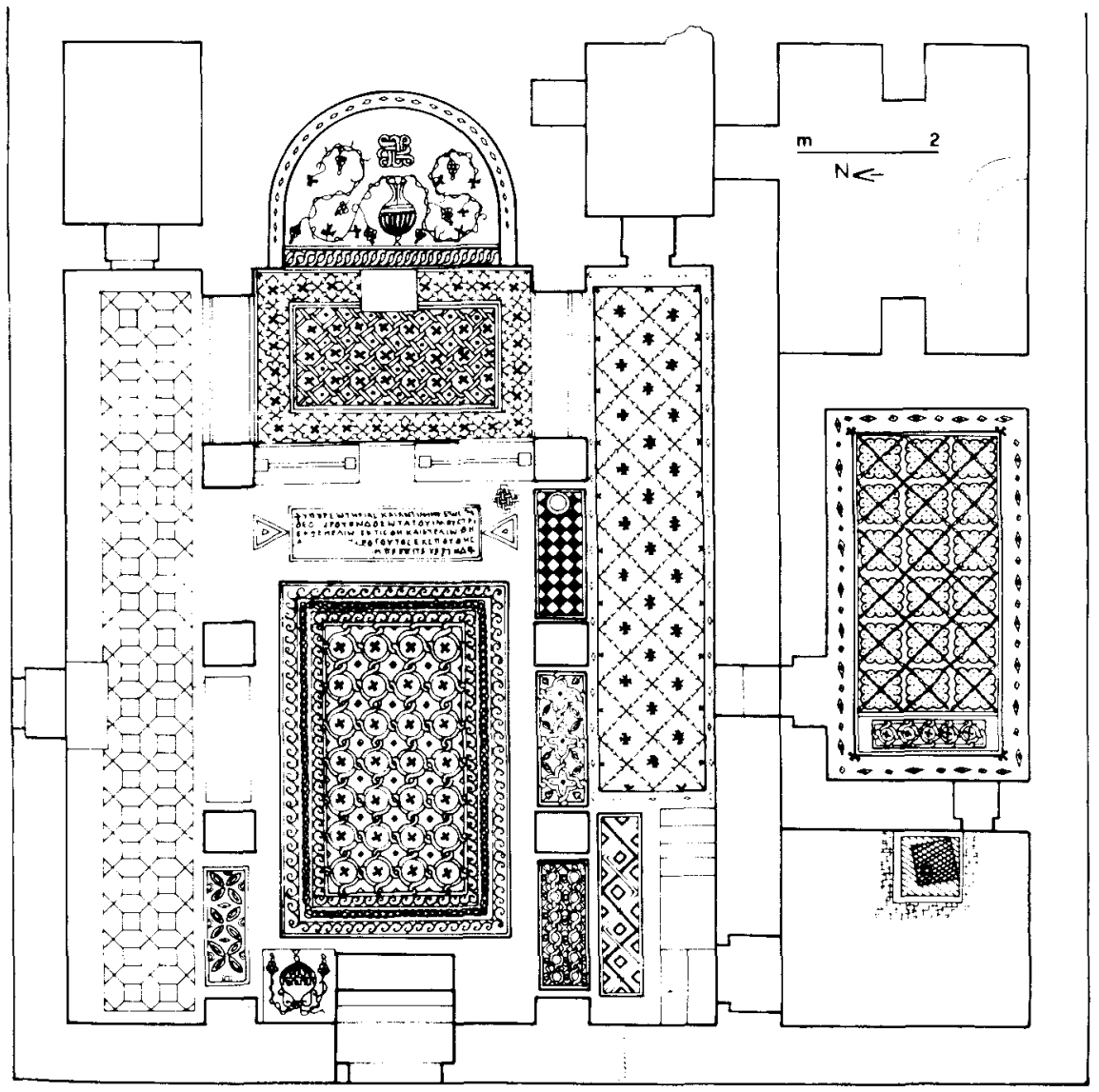

Fig. 7. Iglesia de ed-Deir en Ma'In.

bizantino ${ }^{28}$. Este autor ha intentado averiguar la antigüedad de estos espacios y rituales liturgicos. Para ello ha recabado en las fuentes escritas contemporáneas a los monumentos que no ha desvelado la arqueología, cotejando continuamente unas y otros. El método me parece insuperable pues trata de evitar anacronismos y descontextualizaciones geográficas.

28 Descoeudres. G. Die Pasthophorien im syrobyzantinischen Osten. Eine Untersuchung zu architektur- und liturgiegeschichlichen Problemen. Wiesbaden, 1983, passim. 
Las conclusiones de este espléndido trabajo -de las que los especialistas apenas se han hecho eco- son muy claras. Las pastoforias que se encuentran en las iglesias siriacas antes de la invasión islamica no cumplen esta funcionalidad. En esta época no existia una ceremonia para la prothesis que requiriese un lugar especial ad hoc. cosa que puede observarse en la diversidad morfologica de estas cámaras situadas en el lado norte del ábside. En cuanto al diakonikon existe una polivalencia de funciones que van desde la simple sacristia, a la utilización por los diáconos como lugar de reserva de la liturgia, pasando por la ubicación de una memoria martyrum, hasta llegar a ser utilizado como baptisterio. Esto demuestra la heterogeneidad de significados que pudieron tener estas cámaras adosadas al ábside para las comunidades cristianas de Siria en esta época ${ }^{29}$.

Centrándonos ahora en las iglesias del territorio de Madaba, volvamos por un momento a la localización de las mensae de ofrendas en relación con la ceremonia de la prothesis. Como ya hemos señalado, los pocos casos, más o menos dudosos, que han sido identificados como tales no se sitúan nunca en la cámara norte, sino junto a la línea del cancel, sea en el norte o en el sur. La interpretación de estas improntas como mesa de ofrendas puede tener una base litúrgica más o menos fidedigna, dado el grado de evolución de esta ceremonia en los siglos $v$ $y v^{30}$.

Si fijamos nuestra atención en el espacio que, entre los especialistas, se ha convenido en llamar "prothesis» comprobamos la ausencia de mobiliario litúrgico que permita identificarlo como tal. En la Iglesia de San Esteban de Um er-Rasâs (fig. 9), el ambiente septentrional sufrió varias modificaciones que describe Piccirillo ${ }^{31}$. Inicialmente cuadrado, fue transformado en un ambiente absidado. En la fase contemporánea al mosaico de la nave norte, un cancel lo dividia de la iglesia, siendo colocado un altar sobre el mismo mosaico. En una segunda fase, se construyó un ábside en la pared oriental y un muro sustituyó al cancel, abriéndose un nuevo acceso por el muro norte.

Evidentemente, por lo que se refiere a la segunda fase de este ambiente septentrional, no cabe la menor duda de que se trata de una capilla lateral, cuyo acceso desde la iglesia se tapia. La primera fase, en

29 Descoevdres, obra citada, pág. 75.

${ }^{30} \mathrm{Cfr}$. el comentario sobre la ceremonia de la Proskomide en Descoeudres, obra citada, págs. 16-17

31 Piccirillo, obra citada, pag. 283 

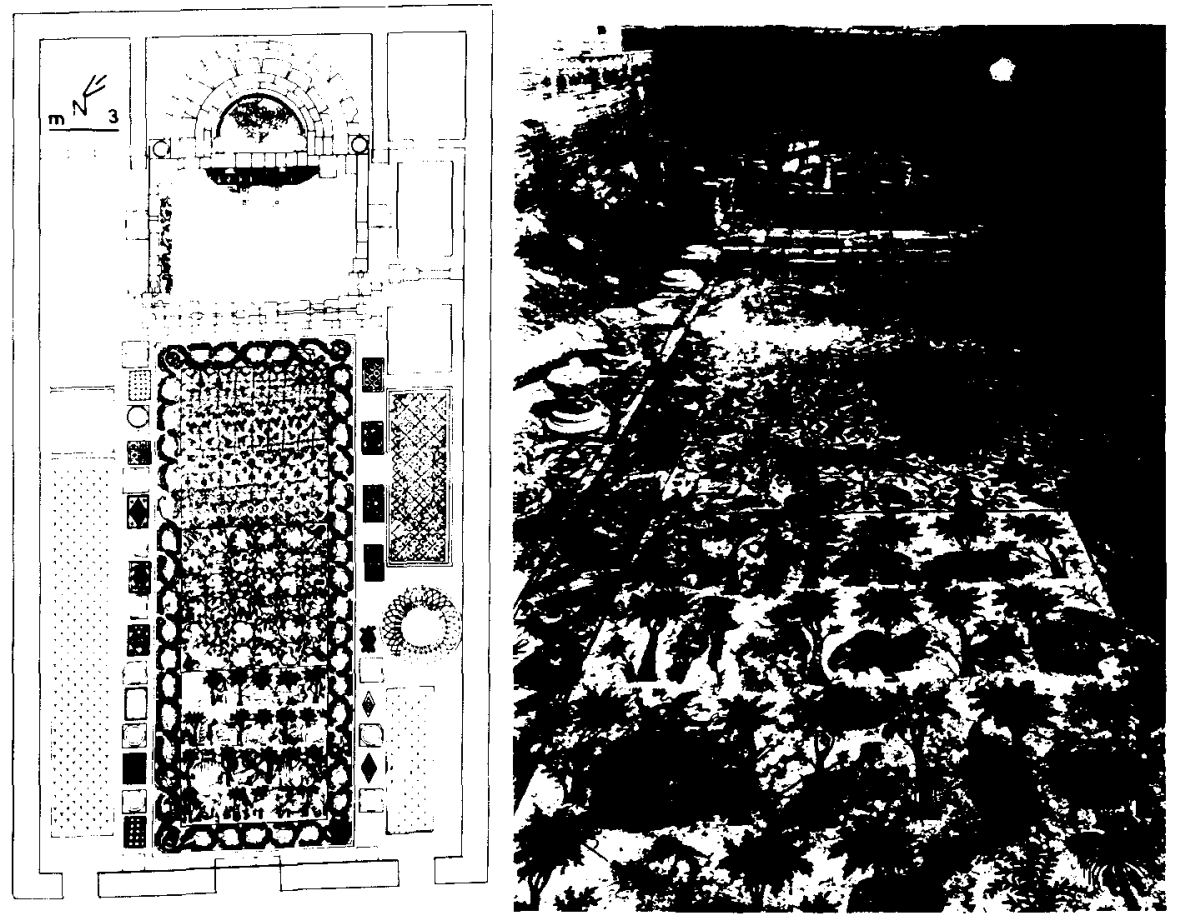

Fig. 8. Iglesia de El Khadir.

cambio, podria relacionarse con una prothesis, por tener una mensa de altar en una ambiente comunicado con la nave norte de la iglesia. Claro está que las huellas arqueológicas de un altar poco nos demuestran la utilización litúrgica que de él se hacia.

Estoy convenida, sin embargo, de que las conclusiones a las que ha llegado G. Descoeudres sobre la ceremonia de la prothesis son correctas, y me decanto por interpretar otro tipo de utilización de este espacio litúrgico, más acorde con la función que desempeñó en la segunda fase: una capilia lateral. Volveremos más adelante sobre esta cuestión de las capillas adosadas a las iglesias de Madaba y su evolución en la historia de la liturgia de esta región.

Por lo que se refiere a los diakonika, el problema resulta ya distinto. La diferencia estriba en que la epigrafía nos ha desvelado la existencia de este espacio litúrgico con todas las letras de su nombre: diakonikon. La inscripción proviene del Memorial de Moisés, de lo que Piccirillo llama el "antiguo diakonikon-baptisterio", que alude a la reconstrucción y em- 
bellecimiento del diakonikon mediante una fuente de regeneración cubierta por un cimborio, en agosto del 531.

Este espacio litúrgico se sitúa en el lado norte del santuario, en un aula adosada al cuerpo principal de la iglesia, dividido en tres naves. El marco arquitectónico no corresponde con las habituales cámaras adyacentes al ábside, interpretadas erróneamente hasta ahora por los especialistas como pastophoriae. Además, esta ubicación es contradictoria con las prescripciones del Euchologion para el diakonikon que, según esta tradición litúrgica, debe situarse al sur del ábside. Al romperse tantos esquemas, salen a relucir muchas más incógnitas: ¿cuál fue la utilidad litúrgica que tuvo en su día este espacio? ¿es posible que tuviera varias funcionalidades?

La lectura de la inscripción del mosaico de este ambiente viene a sumar más dificultades a la interpretación de este espacio litúrgico. La cámara o aula -o cualquiera que fuese la fórmula arquitectónica que tenía este diakonikon- se reconstruye y se embellece con la ubicación de una piscina bautismal cruciforme. Esto quiere decir, si nuestra lectura no es errónea, que el diakonikon - ya existente- es remodelado y convertido en baptisterio, sin perder su funcionalidad de diakonikon, el año $531^{32}$.

No sé hasta qué punto es correcta litúrgicamente la utilización de un espacio como lugar de reserva de los diáconos durante el oficio, a la vez que sea el lugar donde se celebra el sacramento del bautismo. Vayamos por partes. La identificación arqueologica de un diakonikon tiene que ser su comunicación con el bema o el santuario de la iglesia para permitir la libre circulación durante la celebración de la synaxis. Por otra parte, la presencia de la piscina bautismal en el ambiente hace de éste, indiscutiblemente, un baptisterio.

Si observamos atentamente las plantas que publica Piccirillo del Memorial de Moisés (figs. 3 y 4), no podemos afirmar si este espacio tenia comunicación con el bema, porque no está representado en la planimetria. Existen dos accesos a esta aula que no corresponden a las paredes contemporáneas al espacio del que estamos hablando. Hay que añadir que también resulta muy vago el trazado de la planta, tanto del santuario primitivo del siglo IV, como de sus posteriores refacciones anteriores a la época justinianea, que seria interesante completaran los excavadores con un exhaustivo análisis arqueológico. La función de este ámbito como dia-

* Piccirillo. Obra citada, págs. 156-157. 
konikon. sin embargo, resulta bien clara, según reza la inscripción del mosaico que lo cubre. Por lo tanto, ha de existir una comunicación con el bema del santuario, anterior al 531. La búsqueda de este acceso podría además arrojarnos alguna luz sobre la disposición de la cabecera de esta iglesia antes del siglo VI.

Del mismo modo, si se comprobara la existencia de tal acceso aun después de las remodelaciones del 531 que complementan o convierten este espacio en baptisterio. sabriamos si su funcionalidad litúrgica fue doble o simple. Por lo tanto. hasta realizar estas comprobaciones. no podemos hablar del "baptisterio-diakonikon" del Memorial de Moises como espacio con doble funcionalidad litúrgica ${ }^{33}$.

Diferente es el caso cuando la comunicación con el bema está bien clara. En la diócesis de Madaba encontramos tres iglesias que tienen un dispositivo especial de un espacio delimitado por canceles, incluyendo la cámara adosada al sur del ábside, el bema y el santuario. Esta instalación litúrgica la encontramos en la Iglesia de El Khadir (fig. 8), en la del diácono Tomás (fig. 6) y en San Esteban de Um er-Rasâs (fig. 9).

En la Iglesia del diácono Tomás la barrotera de canceles está colocada sobre el pavimento de mosaico, por lo que la habilitación de este espacio litúrgico parece tardia. En las otras dos iglesias, la accesibilidad a la cámara sur está protegida por los canceles que asi aseguran su exclusiva utilización por el clero. Estos tres ejemplos representan. en mi opinión, tres diakonika en el sentido litúrgico de la palabra.

El diakonikon de San Esteban de Um er-Rasâs presenta un nicho a la manera de armariete en la pared norte. Su utilizacion. siendo este espacio una sacristía, puede deducirse sin problemas: un lugar para guardar los objetos litúrgicos del culto. Otras iglesias de la diocesis de Madaba tienen tambien estos armarietes; unas en la camara sur - además de la ya citada de San Esteban--: La Iglesia del profeta Elias y la de ed-Deir en Ma'in (fig. 7); otras en la camara norte. como la de San Sergio de Um er-Rasâs (fig. 9). La Iglesia de En-Nitl contiene nichos de este tipo en la cámara norte y en la sur.

Hay que destacar que estos nichos-armarietes de las piezas adyacentes al ábside se sitúan siempre en la pared más cercana al santuario, es decir. si están en la habitación sur, en la pared norte, y. si en la norte. en la pared sur. En mi opinión este hecho no es casual y reviste una

Supongo que Descoevdres. G.. obra citada. pag. 75. se basa en este ejemplo del Memorial de Moises para aceptar la funcionalidad de un diakonikon como baptisterio. 
A proposito de las iglesias y mosaicos de Madaba. Problemas ...



Fig. 9. Complejo eclesiástico de San Esteban de Um er-Rasâs. 
enorme importancia puesto que busca la proximidad filacterica del sancta sanctorum de la iglesia. Tanto es así, que sería interesante cuestionarse la sacralidad del contenido de estos nichos-armarietes, con algo tan sagrado como las reliquias de un mártir o un santo.

Sabemos por la Vida de San Euthymio. de Cirilo de Scitopolis, que el diakonikon de una iglesia de Palestina tenia un nicho-armariete donde, junto al ajuar litúrgico. se guardaban las reliquias de la iglesia ${ }^{34}$. Esto demuestra la función de los diakonika como martyrion, funcionalidad que no es exclusiva, sino que puede combinarse perfectamente con la de sacristia - como en el caso aquí aducido-, lugar para guardar los tesoros más preciados de la iglesia (skenophylakion. thesaurum, gazophylacium), y otras funcionalidades litúrgicas, acordes con la solemnidad expresa en la forma de construcción de este espacio.

Esta pluralidad de funciones para el diakonikon, como espacio litúrgico, no nos permite enfatizar el carácter de estos ambientes como martyria, como pretende Duval ${ }^{35}$. El culto de las reliquias de los mártires tuvo siempre un lugar significativo, pero no importante en la iglesia de Siria. Las fuentes apenas hablan del culto de los mártires, sino es para celebrar la divina liturgia el dia del natalicio, con carácter conmemorativo. De hecho la tradición siriaca dispone las reliquias en ambientes laterales o cercanos a la iglesia, nunca bajo el mismo altar que considera el martyrion de Cristo ${ }^{36}$.

Antes de dar por concluido este comentario sobre la disposición y funcionalidad litúrgica de los diakonika, querriamos detenernos en el Complejo de Um er-Rasâs. El núcleo principal de este complejo lo forman las iglesias del Obispo Sergio y San Esteban. Pero lo que realmente llama la atención es la ordenación espacial que guardan entre sí: la iglesia de San Esteban parece el diakonikon de la del Obispo Sergio. Claro está que se trata de dos iglesias independientes; los excavadores hacen a la del Obispo Sergio más antigua que la de San Esteban, la cual Piccirillo data en la segunda mitad del siglo vill, fecha que corresponde a su última pavimentación de mosaico, pero cuya construcción ha de ser muy anterior, cosa que, evidentemente, necesita de una comprobación arqueologica, aunque existen ciertos indicios para asegurar una mayor antiguedad, como se verá a continuación.

Schwartz. E.. (ed.), Kyrillos von Skythopolis, (Texte und Untersuchungen zur Geschichte der altchristlichen Literatur. 49, 2). Leipzig. 1939. pags. 59 y 69.

DUval, articulo citado. pág. 204.

"Descoevdres, obra citada. pags. 73-74. 
Si tomamos en nuestras manos las fuentes de la liturgia hierosolimitana, nos encontramos con una grata sorpresa. La fiesta conmemorativa dedicada a San Esteban, protomártir, tenía lugar en el diakonikon de la Iglesia de Sión, el día 27 de diciembre, lo cual resulta muy interesante. La leyenda de la invención de sus reliquias hace a San Esteban archidiácono de la Iglesia de Sión; después de su lapidación - que los textos sitúan en diversos lugares-, su cuerpo fue encontrado en el 415 en Caphargamala, desde donde fue trasladado al diakonikon de la Santa Sión, donde permaneció hasta el 438/439, año en el que fue erigido - a expensas de la emperatriz Eudoxia-- su primer martyrion que no fue consagrado solemnemente hasta el 15 de junio del $460{ }^{37}$. En el siglo vi aún se mostraban en el mismo anexo las piedras de la lapidación de San Esteban ${ }^{38}$.

De los testimonios de la liturgia de Jerusalén -el Leccionario de Jerusalén-, la tradición más explícita sobre el lugar de la conmemoración de la fiesta de San Esteban es la de los leccionarios georgianos. En estos textos, cuyos origenes remontan al siglo $\mathrm{v}$, se constata que la fiesta más antigua del protomártir, la del 27 de diciembre, se celebra en el diakonikon de Sión. En el mismo lugar se celebran el tercer dia de Epifania y el martes de Pascua, estaciones que, segun los leccionarios armenios, tienen por escenario el martyrium de San Esteban ${ }^{39}$.

$\mathrm{Ni}$ los leccionarios georgianos ni los armenios recogen en sus calendarios una fiesta especial en honor de San Esteban en memoria de la depositio de sus reliquias el 15 de mayo del 438/439, ni de la dedicación el 15 de junio del 460 del templo que se erigiera al norte de Jerusalén. La fiesta del 27 de diciembre que contemplan los documentos armenios y georgianos es una fiesta de naturaleza indeterminada; podria ser anterior incluso al 415 o quizá conmemorar la traslación de las reliquias tras su hallazgo el 26 de diciembre del 415. La conmemoración de estos acontecimientos de la deposición y dedicación del templo construido por

Epistola Luciniani ad omnem ecclesiam. de revelatione corporis Stephani martyris primi et aliorum. PL. 41. cols. 815-816.

${ }^{38}$ GaBic, G., Les chapelles annexes des Eglises, Byzantines. Fonction liturgique et programmes iconographiques. Paris, 1969. pag. 13. Nau. F., “Melanges: 3. Sur une premiere redaction du martyre de Saint Etienne et sur la version syriaque du recit de linvention". Fevue de l'Orient Chretien, 11. (1906). págs. 203-212. Lagrange. M. J. Saint Etienne et son sanctuarire à Jerusalem. Paris, 1894. MOMERT, C. Saint Etienne et ses sanctuaires à Jerusalem. Leipzig-Paris. 1912. VAILHE, S.. "Les eglises Saint-Etienne a Jerusalem", Revue de lOrient Chretien. 12 (1907), pags. 70-89.

39 TARCHNisvili. M., "Le grand lectionnarire de IEqlise de Jerusalem (V-VIII siecle), C.S.C.O. 188, 189, 204 y 205. Louvain. 1959-1960 
Eudoxia hicieron su entrada en los leccionarios y calendario palestinogeorgiano, otros testimonios más tardios del ritual hagiopolita. En este sentido, resulta muy claro el nombre dado por los leccionarios georgianos al santuario de Esteban del 438/439. que no es denominado nunca martyrium de San Esteban. sino San Esteban ${ }^{10}$.

En conclusión. podemos decir que la liturgia del Leccionario de Jerusalen. tanto en sus manuscritos armenios como georgianos. sitúa la fiesta de la conmemoración del mártir Esteban en el martyrium situado en el diakonikon de la iglesia de la Santa Sión.

Si ponemos en relación esta ordenación espacial hierolimitana con el esquema de la disposición de las iglesias de Um er Rasâs, veremos que concuerda con el de la Santa Sión en Jerusalén. La propia distribución de las iglesias hace tomar a la Iglesia de San Esteban la apariencia del diakonikon de la del obispo Sergio.

La dedicación de la Iglesia de San Esteban la conocemos por la inscripción situada en el escalón que conduce al bema. donde se le llama protodiácono y protomártir. La situación de las inscripciones dedicatorias suele colocarse en la puerta del bema. En el caso de la Iglesia del obispo Sergio, la dedicación la ha tomado Piccirillo de la inscripción de mosaico que decora el bema, el cual fue dispuesto en tiempos del obispo Sergio. Pero Piccirillo no se ha percatado que otra inscripción - situada ésta también en el escalón que conduce al bema - hace alusión nada más y nada menos que a la Santa Sión: "Ama el Senor la puerta de Sion por encima de todas las tiendas de Jacob" (salmo 86,2, texto de la LXX). En mi opinión, la advocación de la Iglesia del obispo Sergio es muy clara, se trata de la Santa Sión ${ }^{41}$ (fig. 10).

El esquema del programa constructivo coincide totalmente con el de la ciudad santa de Jerusalén. El problema estriba en la datación que Piccirillo ha dado a este complejo eclesiástico, basándose únicamente en las fechas de las inscripciones de los mosaicos. Io cual considero un error metodológico. La Iglesia del obispo Sergio la fecha en el 586, en plena época justinianea, lo cual no desbarata nuestra hipótesis, como se verá. La que si desajusta cualquier intento de interpretación es la datación de la Iglesia de San Esteban en la segunda mitad del siglo vill.

40 Renoux. A. Le codex armenien Jerusalem 121 (2 vols.), PO. 35 y 36. Brepols. 1969 1971. págs. 198-202: Idem. "Un manuscrit du lectionaire armenien de Jerusalen". Le Museon. 74. 3-4 (1961), págs. 361-385. Idem, "Liturgie de Jerusalem et lectionnaires armeniens. Vigiles et année liturgique". Lex Orandi, 35. París. 1963. pags. 167-199. ConybeARE.

F. C. Rituale Armenorum. Oxford. 1905.

¿ Piccirillo, obra citada, pág. 281 


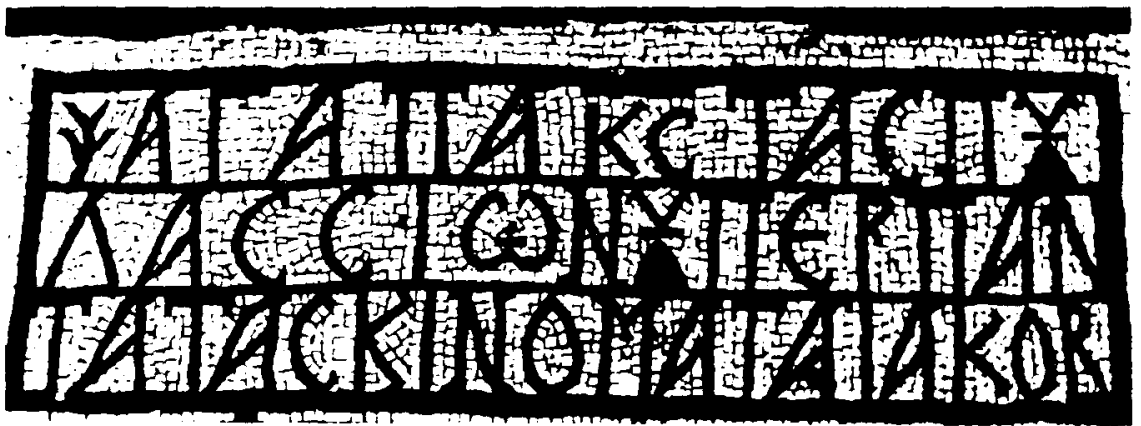

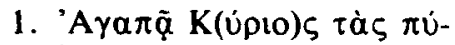

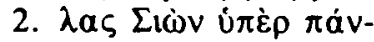



Fig. 10. Inscripción dedicatoria con el nombre de la Santa Sión en la lglesia del obispo Sergio de Um er-Rasâs.

De las dos inscripciones fechadas de la Iglesia de San Esteban, la única que se fecha sin duda alguna en el siglo vill es la del bema, en el año 756. Esto ha llevado a los excavadores a enfatizar la actividad constructiva de Madaba después del triunfo del Islam. Sin embargo, no podemos olvidar que la fecha de una pavimentación no tiene que coincidir necesariamente con la de la erección del edificio. Nótese, por otra parte, que la decoración del mosaico del bema es "totalmente" geométrica, cosa que iria muy bien para la época en que fue construido, acorde para evitar las furias iconoclastas de los musulmanes. La otra inscripción que fecha esta pavimentación en época tan tardía es la misma dedicatoria de la que ya hemos hablado. De todas formas, quiero mostrar mi escepticismo, por cuanto -como reconoce el mismo Piccirillo ${ }^{42}$ - las dos cifras de la fecha caen en el sitio que sufrió una ruptura y que fue restaurado después. Esta inscripción acompañaba un plafón decorativo con figuras entre árboles frutales que fueron destrozadas por los iconoclastas; dichos destrozos fueron reparados por teselas blancas con simbolos florales. Por lo tanto, es probable que la fecha de la inscripción corresponda a esta reparación del mosaico y no a la ejecución del programa iconográfico de toda la iglesia. En todo caso, constituye un argumento de un valor histó-

${ }^{42}$ PICCIRILLO, obra citada, pág. 293. 
rico indiscutible que demuestra la continuidad del culto en estas iglesias incluso bajo la égida del Islam.

Para lo que aqui nos interesa, sin embargo, esta discusión sobre la datación de la pavimentación de mosaico de la Iglesia de San Esteban resulta estéril. Lo importante es investigar la fecha de su construcción, la cual requiere una revisión arqueológica que promete ser muy interesante y que esperamos realicen en un futuro próximo el equipo del padre Piccirillo.

Por la reproducción del esquema constructivo del modelo de la Santa Sión de Jerusalén, estoy convencida de que la planificación de estas dos iglesias de Um er-Rasâs se hizo en un mismo momento ${ }^{43}$. Pero, ¿en qué época?

Para el modelo de la Santa Sión hagiopolita, no movemos en unos limites cronológicos bastante claros. Si las reliquias de San Esteban fueron halladas en el año 415, su deposición en el diakonikon de la Iglesia de Sión ha de ser posterior a esta fecha. Por tanto, cualquier reproducción de este modelo ha de fecharse, al menos, despues de este acontecimiento, de la segunda mitad del siglo $v$ o posteriormente.

Teniendo en cuenta los avatares históricos de esta zona del territorio de Madaba y, en general, la zona de Siria, frente a las disensiones entre los patriarcados de Antioquia y el de Jerusalén a causa del movimiento monofisita de Antioquía, creo que la reproducción del modelo hierosolimitano en esta zona de la provincia Arabia, reviste un significado especial para la politica eclesiástica. Se trata de una maniobra política en materia religiosa en querer demostrar la prepotencia del patriarcado de Jerusalén, fenónemo éste que ya habia señalado Dounceel-Voûte en relación al programa iconográfico del mosaico de la Iglesia del Mapa de la ciudad de Madaba, programa que, curiosamente, se repite en San Esteban de Um er-Rasâs: la representación de la ciudad santa de Jerusalén en el lugar más prestigioso - próximo al bema- de la nave de la iglesia ${ }^{44}$.

La protección decisiva del patriarcado de Jersusalén en estas disputas eclesiásticas fue realizada por Justiniano, a partir del $\|$ Concilio de Constantinopla (553) ${ }^{45}$. Por esta razón, y, dado que la mayoría de los

${ }^{43}$ Esto no exime. sin embargo, que este programa constructivo aprovechase estructuras ya existentes, quizá edificios de culto. Sólo una revisión exhaustiva de la planimetria puede darnos la respuesta.

4 Supra, nota 2

Supra, nota 2 
mosaicos de las iglesias de la diócesis de Madaba se fechan en época justinianea, creo que el programa arquitectónico de la construcción de las iglesias de Um er-Rasâs según el modelo de la Santa Sión de Jerusalén, obedece a esta política eclesiástica justinianea y en tal época debe datarse. Ahora se comprenderá porque deciamos que la datación en el 586 de la Iglesia del obispo Sergio - la otra Santa Sion- se ajusta a nuestra interpretación. La prepotencia de Jerusalén no sólo se manifestaba por la imposición de un rito litúrgico, sino que adquiria también una expresión plastica en el espacio litúrgico de las iglesias.

6. Baptisterios. Hay que destacar que, entre las 25 iglesias que nos presente Piccirillo del territorio de Madaba, sólo tres de ellas cuentan con un espacio litúrgico reservado para el conferimiento del sacramento del bautismo: la Catedral de Madaba, el Memorial de Moisés y las iglesias de Dhibân.

Lamentablemente la Iglesia de Dhibân, la antigua Dibón, fue objeto de una excavación inacabada, realizada por una misión americana de 1950 a 1953. Fue exhumado un complejo eclesiástico compuesto por una iglesias absidada al norte, otros restos no identificados y un área con una piscina bautismal cruciforme aislada, cuya relación con esos edificios de culto es, por ahora, desconocida. Su conocimiento no sirve más que para saber de su existencia ${ }^{46}$.

La presencia de un espacio reservado al bautismo en el Memorial de Moisés (figs. 3 y 4 ), resulta, por el contrario, un dato muy interesante ya que se trata de un gran centro de peregrinación. La veneración de los peregrinos por los lugares santos y el deseo de recibir el bautismo ad martyres o ad sanctos es un fenómeno muy conocido por los especialistas de arqueologia cristiana ${ }^{47}$. Sin duda esta necesidad litúrgica fue lo que determinó el condicionamiento de un espacio reservado a tal fin. primero, en el antiguo diakonikon (datado por la inscripción del mosaico en el 531), y, después - una vez amortizado éste- la construcción de un segundo baptisterio sobre la capilla funeraria originaria, datado en el $597 / 598$.

El otro complejo eclesiástico que contiene un baptisterio es to que Piccirillo ha convenido en llamar la Catedral de Madaba (fig. 1), no tanto por disponer de un espacio dedicado al bautismo, sino tambien por las dimensiones gigantescas de la iglesia, que, dicho sea de paso, no está

PICCIRillo. obra citada. pág. 260.

$\because$ Fevaler. P. A. "Baptisteres, martyrs et reliques". RAC, 62 (1986). pags, 109-138. 
totalmente excavada. De hecho, la intervención arqueológica del padre Piccirillo se centra en el atrio de la basilica, donde se levanta, además del baptisterio, la Capilla de San Teodoro. una cisterna en un patio central y un ambiente intermedio entre el patio y el baptisterio que un acto de vandalismo ha impedido aclarar la naturaleza del mismo. Piccirillo propone un circuito para el desarrollo de la liturgia bautismal ${ }^{48}$.

La identificación de la cisterna del patio central como el lugar de reserva de agua bendita me parece probable; así como el paso de los neófitos del baptisterio a la iglesia para participar del sacrificio eucarístico ${ }^{49}$. Lo que no me parece tan acertada es su interpretación de la Capilla de Teodoro como lugar donde los catecúmenos hacian la renuncia a Satanás. La argumentación de Piccirillo para hacer de esta capilla el escenario de esta ceremonia de la liturgia bautismal reside en la occidentalización de la misma, es decir, en la ubicación de altar en el ábside, construido hacia el oeste. Los candidatos al bautismo proferian la renuncia a Satanás dirigiéndose hacia occidente. lugar de la oscuridad. las tinieblas y del mal. El ritual bizantino del bautismo contemporáneo a la capilla erigida a finales del siglo vi contempla la esputación de los "competentes" hacia occidente ${ }^{50}$. Una capilla con un altar, por muy secundario que sea. no es el escenario apropiado para realizar esta ceremonia, sobre todo, teniendo en cuenta que el altar estaba consagrado a San Teodoro. Pienso que más bien tendría lugar en el patio de esta iglesia.

La intención del comentario sobre los baptisterios no es. sin embargo, entrar en cuestiones de detalle. Resulta más interesante, en mi opinión, comprobar que la diócesis sólo cuenta con tres instalaciones bautismales, 0 , dicho de otra manera, que de las 25 iglesias registradas en esta diócesis, 23 carecen de este espacio litúrgico bautismal. En este caso, es más significativo el argumento ex silentio.

¿Qué conclusiones tenemos que extraer de esta ausencia? ¿Es que en esta parte de Palestina y Arabia el bautismo sólo lo confería el obispo en la catedral y en los lugares más prestigiosos, como el Memorial de Moisés?

*Piccirillo. obra citada. pags. 37-38. Ibidem. "l battisteri bizantini di Giordania". Nocere Sancta, I. Roma. 1985, págs. 345-356.

"Godoy. C.. "Baptisterios hispanicos (siglos Iv al vIII): Arqueologia y Liturgia". Actes du XI C.I.A.C. (Lyon. Vienne. Grenoble. Geneve et Aoste. septembre, 1986). Roma-Ciudad del Vaticano, 1989, pags. 607-634.

5. JANERAS. V. S.. L'iniziazione cristiana nella tradizione liturgica orientale. Roma. 1968. págs. 51-53. 
En general. los especialistas en historia de la liturgia están de acuerdo en que el conferimiento del bautismo era nominalmente del obispo, y que éste delegaba esta potestad entre los presbiteros. excepto en la celebración solemne de la vigilia de Pascua, en occidente, y el día de Epifania, en oriente, que se oficiaba por el propio obispo en la catedral ${ }^{51}$. En principio, la presencia de un baptisterio no es argumento suficiente para identificar una catedral, sino que se interpretan como iglesias parroquiales regentadas por presbiteros.

De todo esto podemos deducir que las 23 iglesias de la diócesis de Madaba que carecen de baptisterio --reservándonos para las que la excavación no ha sido finalizada - no tiene carácter parroquial. Este dato es muy importante por cuanto refuerza los lazos de dependencia de estas iglesias con la sede episcopal, en materia de decidir quiénes eran dignos de ser aceptados en la comunidad cristiana. De hecho esta dependencia tiene su reflejo también en la epigrafía de los mosaicos en la que siempre se nombra al obispo con un gran respeto y veneración, cosa que ha permitido a Piccirillo reconstruir la lista episcopal de la diócesis de Madaba.

Este hecho me parece muy importante por su significación histórica. Constituye otro testimonio de una politica religiosa fuerte y centralizada - a sumar con los que ya hemos ido apuntando-- muy acorde para los momentos de conflictividad religiosa existente entre ortodoxos y monofisitas. Resulta pues muy ilustrativo que, en una época de desconfianza y de heterodoxia latente, vinculada a los intereses de las altas jerarquías y de la propia corte imperial, el obispo se reservara la potestad de controlar la admisión de nuevos fieles en la comunidad cristiana ortodoxa mediante el bautismo, no sólo en la catedral, sino también en el centro de culto más prestigioso de la diócesis, el Memorial de Moisés.

En esta hipótesis quedan, sin embargo. algunas incógnitas por despejar. Si la política religiosa episcopal es fuerte y centralizadora. como parece ser, ¿por qué hay tantas iglesias en las diócesis de Madaba? La interpretación de este fenómeno preferimos esbozarla junto al problema de las capillas adosadas a las iglesias, verdaderas iglesias en miniatura.

7. Las capillas contiguas a las iglesias de Madaba. Uno de los fenómenos que más llama la atención de las iglesias de esta zona de Jordania es la abundancia de capillas laterales adosadas o próximas a

Godor. C.. Baptisterios hispanicos (siglos $\mathrm{N}$ al vili): arqueologia y liturgia. Tesis de licenciatura, febrero 1985. Universidad de Barcelona (pro manuscripto). 
un centro de culto principal. En esta misma linea, aunque en un diferente grado del mismo fenómeno, creo que puede incluirse también la gran profusión de iglesias - un total de veinticinco - en un territorio diocesano de reducida extensión. Esta multiplicidad es aún más sorprendente si consideramos que diez de estas iglesias se hallan en la misma ciudad de Madaba.

Una ciudad con una decena de iglesias de dimensiones no muy grandes debería tener una comunidad suficiente para justificar la construcción de una o dos iglesias de gran envergadura que dieran cabida a todos los fieles. Pero esta solución no fue escogida.

La multiplicidad de pequeñas iglesias refleja un cambio en las costumbres liturgicas de tradición paleocristiana que tiene su traducción directa sobre el espacio físico de la arquitectura.

R. Krautheimer ${ }^{52}$ y C. Mango ${ }^{53}$ atribuyen esta transformación de la liturgia bizantina a la influencia del monaquismo, cosa que en su fundamento parece correcta. Muchas de las innovaciones de la práctica eclesiástica de Bizancio provienen del monaquismo. La cuestión es saber el mecanismo con el que tuvo lugar este cambio.

T. F. Mathews ha hecho un estudio aproximativo sobre el tema que me parece muy sugerente ${ }^{54}$. Su tesis explica la multiplicidad de iglesias "en miniatura" por una tendencia progresiva de la liturgia hacia una "privatización». Todas estas capillas tienen el mobiliario litúrgico indispensable para la celebración de la synaxis eucarística. La aparición de este fenómeno la hace remontar Mathews al siglo VI, tomando como referencia el Monasterio de Santa Catalina en el Monte Sinai (548-560), cuya iglesia sigue un esquema comun a las primeras basilicas con una notable aparición de capillas en torno a su perimetro; estructuralmente, todas pertenecen a la fábrica original de la iglesia justinianea.

La influencia monástica la explica Mathews por la necesidad litúrgica de los monjes de celebrar la eucaristia a diario, teniendo en cuenta que la práctica antigua cristiana - que continuó hasta la Edad Media en muchos lugares- restringía la liturgia pública a los sábados y los domingos.

52 Krautheimer, R., Early Christian and Byzantine Architecture. Middlesex, 1965. paigina 247.

5:3 Mango, C.. Byzantine Architecture. Nueva York. 1974, pags. 197-198.

5. MATHEWS. T. F., "Private Liturgy in Byzantine Architecture: towards a Re-appraisal". CA, 30, 1982, páginas 125-138, passim. 
De esta manera surgía así una necesidad de crear un espacio de culto reducido que permitiera la celebración privada de los monjes ${ }^{55}$.

Los postulados de Mathews parten del supuesto de que existian centros de culto mixto, es decir, iglesias con una comunidad monástica que hacian a la vez de parroquia. Sin duda estos centros existieron, como lo fue el caso que tenemos en la diócesis de Madaba del Memorial de Moisés. Pero no podemos olvidar que éste eran un centro de peregrinaje, en los que si es frecuente la presencia de comunidades monásticas ${ }^{56}$, y que tales ejemplos no dejan de ser excepcionales. El monaquismo, sobre todo en Siria, tiene un carácter eremítico y sus iglesias son, en la mayoría de los casos, rupestres y propias, donde se acentúa aún más el tono intimista de su devoción litúrgica.

En mi opinión, existe otro factor más importante que el monaquismo que conduce también a esa necesidad de la privatización de la liturgia. Se trata de la importancia adquirida en esta epoca por la clerecia (presbiteros y diáconos), cuyo ordo crece en número y en prestigio. Este ordo canónico, desarrollado a partir del núcleo de la catedral -con la que jamás rompian sus lazos de dependencia-, tenian una organización de vida en común en la que se incluia también la oración y la celebración de la eucaristia. No puede negarse que en esta organización recibieran una fuerte influencia del monaquismo, pero, teniendo en cuenta que la codificación de las regulae monásticas es bastante tardia y que tan solo circulaban unas sentencias de los Padres para el comportamiento de los monjes, no podemos asegurar radicalmente si la influencia fue unidireccional del monaquismo sobre el ordo canónico, o fue un intercambio de experiencias mutuas entre dos cuerpos del seno de la iglesia que iban desarrollándose a la par ${ }^{57}$.

Esta tendencia hacia la privatización de la liturgia del ordo canónico es a la vez causa y efecto de la multiplicación de pequeñas iglesias y de capillas adosadas a las grandes basilicas. En el caso concreto de Madaba, pequeñas capillas van apareciendo en torno a los dos centros más prestigiosos: en la Catedral, la Capilla de San Teodoro; en el Memorial de Moisés, la Capilla de la Theotokos y el nuevo baptisterio. El ejemplo

Mathews, articulo citado, pág. 136

${ }^{36}$ Godoy. C.. "Poder i prestigi episcopal en relacio al culte de les reliquies dels martirs». Homenatge a Miquel Tarradell. en prensa.

Quiero expresar mi agradecimiento al Dr. Miquel dels S. Gros por haberme hecho reflexionar sobre esta cuestion. Cfr. HuBERT, J.. "La vie commune des clercs el l'Archeologie". Arts et vie sociale de la fin du monde antique au Moyen Age. Ginebra. 1977, págs 90-111. 
de Um er-Rasâs también es ilustrativo de la multiplicidad de estas iglesias en miniatura, además de las iglesias del obispo Sergio - Santa Sión-y de San Esteban de las que hemos hecho un extenso comentario, en el patio contiguo se aderezo otra iglesia occidentalizada que comunica, a su vez, con otra que permanece aún por excavar.

La mutación que experimenta la liturgia bizantina de una práctica comunitaria hacia un culto más intimista y privado es una de las manifestaciones de una nueva concepción litúrgica que acentua el cripticismo de los misterios. La traducción arquitectónica de estos cambios permite reducir las dimensiones de las iglesias, al tiempo que concentran la acción litúrgica en el santuario, el cual va volviéndose más cerrado y opaco con el tiempo. La propia liturgia es el objeto de la veneración de los fieles y las procesiones por las naves -típicas de la época paleocristiana-se sustituyen por meras apariciones ${ }^{58}$.

Las nuevas necesidades del culto requerian nuevos escenarios litúrgicos. En la diócesis de Madaba constatamos una eclosión constructiva, datada por la epigrafía en época justinianea. Pero este auge edilicio suponia un gasto económico tan importante que en ningún modo pudo sufragar únicamente la sede episcopal.

El auge del ordo canónico que hemos subrayado como causa directa de esa tendencia a la privatización de la liturgia bizantina se vio secundado por una forma de piedad de los fieles que se convertian en benefactores, cubriendo los gastos de las nuevas contrucciones, remodelaciones y pavimentaciones de mosaico de las iglesias. La epigrafía de los mosaicos de Madaba constituye, en este sentido, una fuente histórica de primer orden para el estudio del florecimiento de las iglesias privadas.

Entre los benefactores madabitanos pueden encontrarse personajes y variopintos. La epigrafia nos revela nombres de laicos y eclesiásticos entre los benefactores. Entre los laicos figuran nombres de abogados, mosaistas, mujeres y hombres anónimos. hasta miembros de la administración civil y militar (lamprotatoi) y un ecónomo. Con todo, cabe destacar que la mayoria de los benefactores son eclesiásticos, sobre todo. presbíteros y diáconos - miembros del ordo canónico- aunque figuran algunos nombres de igumenos - que son también presbiteros- del Memorial de Moisés, y algún monje.

Mathews. articulo citado. pag. 127 
El sufragio de los gastos de las remodelaciones de las iglesias por parte de los fieles era una forma bastante original de hacer constar su piedad. Hay que destacar que, curiosamente, las iglesias de la diócesis de Madaba no presentan enterramientos dentro de su espacio litúrgico. excepto en el Memorial de Moisés. en ed-Deir en Ma'in. en la de los Santos Apóstoles y en la de los Santos Padres de Kattâbiyan. En todos estos casos las inhumaciones corresponden siempre a personajes eclesiásticos, sobre todo, monjes. Por lo tanto. la única posibilidad de expresar la piedad de los fieles consistia en contribuir al gasto de la pavimentación en mosaico de la iglesia para que figurara su nombre y el de sus seres queridos.

La ley bizantina prevee y promueve la fundación de estas iglesias privadas (eukterioi oikoi), aspecto que ha sido estudiado magistralmente por E. Herman ${ }^{59}$. No solo los grandes terratenientes, sino cualquiera que pudiera esforzarse para expresar su piedad de esta manera podia erigir una iglesia o capilla. Estas iglesias seguian en propiedad de sus fundadores que podian vender, arrendar o dejar en herencia. sin cambiar sus propósitos religiosos una vez establecidos. El fundador escogia el clero -aunque sujeto a la aprobación episcopal-, al que tenía la obligación de mantener, además de cubrir los gastos de los servicios de la iglesia. Las iglesias monásticas llegaron a la misma categoria legal de eukterioi oikol, y las propiedades monásticas acabaron también en manos de los terratenientes, los karistikarios ${ }^{60}$.

El canon 31 del Quinisextum Concilium (692) insiste en que los clérigos que se dedican a celebrar la liturgia o el bautismo en oratorios domésticos de las casas, lo hagan con el consentimiento del obispo del lugar ${ }^{61}$. En el caso de la diócesis de Madaba el acatamiento de la autoridad episcopal era un hecho. Además de figurar siempre el nombre del obispo en las inscripciones de los mosaicos junto al de los demás benefactores, la autoridad del obispo se veía tambien reforzada por el control que ejercía sobre los miembros del ordo canónico que estaban al frente

\footnotetext{
${ }^{9}$ Herman. E.. "Richerche sulle istituzioni monastiche bizantine: typica ktetorika, caristicari e monasteri liberi.. Orientalia Christiana Periodica. II (1940). pags. 293-375. Idem. "Die kirchlichen Einkunfte des byzantinischen Niederklerus". Orientalia Christiana Periodica. 7 (1942), pags. 378-442. esp. 419-425. Idem. "Chiese private e diritto di fundazione negli ultimi secoli dellimpero bizantino". Orientalia Christiana Periodica. 12 (1946). paginas 302321. Idem. "The Secular Church". in Cambridge Medieval History. IV part. 2, Cambridge. 1967. pags. 104-133. esp. 116-125.

b. LEMERLE. P.. “Un aspect du rôle des monasteres a Byzance: Les monasteres données a des laics, les charisticaires». C.A.A.I. 1967. págs. 9-28.

Mansi. IX. pag. 956.
} 
de esas iglesias. La ausencia de baptisterios - que ya hemos comentado anteriormente-, impedía que estas iglesias funcionaran con plena autonomia como parroquias y estrechaba los lazos de dependencia con la sede episcopal. Ciertamente este hecho constituye un rasgo caracteristico de la diócesis de Madaba y, en mi opinión, revela un fuerte control episcopal sobre esta multiplicidad de centros de culto dispersos por el territorio diocesano.

Esta firme politica eclesiástica episcopal, dependiente del patriarcado de Jerusalén, y protegida por la política imperial justinianea, estaba dirigida a una comunidad con un pasado latente de filomonofisismo, propio del patriarcado de Antioquía. Esa fue la trama histórica, no exenta ciertamente de conflictividad, en la que se desarrolló esta soberbia eclosión edilicia cristiana que tan magistralmente nos ha dado a conocer el padre Piccirillo. 